UNIVERSIDADE DE SÃO PAULO

ESCOLA DE ENFERMAGEM DE RIBEIRÃO PRETO

CLAUDIA RIOS CATAÑO

Gravidez na adolescência: análise de resultados nutricionais, obstétricos e neonatais

Ribeirão Preto 
CLAUDIA RIOS CATAÑO

Gravidez na adolescência: análise de resultados

nutricionais, obstétricos e neonatais

Dissertação apresentada à Escola de Enfermagem de Ribeirão Preto da Universidade de São Paulo para obtenção do título de Mestre em Enfermagem.

Área de Concentração: Enfermagem em Saúde Pública.

Inserido na linha de pesquisa: Assistência à saúde da mulher no ciclo vital.

Orientadora: Prof ${ }^{a}$ Dr $^{a}$ Maria José Clapis

Ribeirão Preto 


\section{FICHA CATALOGRÁFICA}

\section{Cataño, Claudia Rios}

Gravidez na adolescência: Análise de resultados nutricionais, perinatais e neonatais. Ribeirão Preto, 2006.

104 p. : il. ; $30 \mathrm{~cm}$

Dissertação de Mestrado, apresentada à Escola de Enfermagem de Ribeirão Preto/USP - Departamento de Enfermagem Maternoinfantil e Saúde Pública.

Orientador: Clapis, Maria José.

1. Gravidez na adolescência. 2. Estado nutricional 3. Recém nascido 


\section{FOLHA DE APROVAÇÃO}

Claudia Rios Catãno

Gravidez na adolescência: análise de resultados nutricionais, obstrétricos e neonatais.

Dissertação apresentada à Escola de Enfermagem de Ribeirão Preto da Universidade de São Paulo, para obtenção do título de Mestre em Enfermagem.

Área de concentração: Enfermagem em Saúde Pública

Aprovado em:

\section{Banca Examinadora}

Prof $^{\mathrm{a}}$ Dr $^{\mathrm{a}}$ Maria José Clapis

Instituição: EERP/USP

Assinatura:

Prof Dr Vanderlei José Haas

Instituição: EERP/USP

Assinatura:

$\operatorname{Prof}^{\mathrm{a}} \operatorname{Dr}^{\mathrm{a}}$ Cristina Maria Garcia de Lima Parada Instituição: UNESP

Assinatura: 
Dedicatória

A mi mamá Charito y mi papá Rubén, por tener el privilegio de ser su hija, por haberme enseñado el significado de los valores y las virtudes sólo con el ejemplo.

A mi hermano Hernan, por la confianza, el cariño y por la ayuda desde el inicio de mi formación académica hasta el día de hoy, todo te lo debo a ti.

Los amo 
Agradecimentos

A Deus, pela vida, por ter me dado saúde e, apesar de estar longe da minha família ter colocado no meu caminho pessoas maravilhosas.

À minha orientadora, professora Maria José Clapis, obrigada pela paciência, apoio, carinho e por estar-me ajudando a realizar este sonho.

Ao professor Vanderlei Haas, pela amizade e por compartilhar seus conhecimentos que trouxeram importantes contribuições para a realização deste estudo.

À professora Cristina Parada, pelas importantes sugestões e contribuições no aprimoramento deste trabalho, no momento da prébanca.

À Maternidade do Complexo Aeroporto (MATER), que me acoIheu com carinho, durante todo o tempo da coleta de dados, e me deu a oportunidade de fazer amizades inesquecíveis.

Às minhas sobrinhas, Claudia e Ariana, por serem elas minha motivação de seguir em frente e não desistir.

À minha família no Peru, por estar a meu lado com sua força, seu apoio nos momentos difíceis e por valorizar tudo o que faço ( $\mathrm{Pa}-$ co, Clara, Alberto, Angela, Ivan, Walter, Hilda, Nona, Tani, Raul, Juan, Consuelo, Gloria, Vicky, Armando, Patrícia, Milagros, Llimi, Marga, Herbert, Sandra, Zaida, Marlene, Humberto e todos os demais), muito obrigada.

Aos meus amigos peruanos, moradores em Campinas SP, Liz, Juan e Glauber, pela amizade, carinho e apoio no momento que mais precisei.

Às minhas amigas, Andréa e Mariana, pela amizade, carinho e apoio constantes, vocês fazem parte da minha vida, da minha história, vocês estão no meu coração. 
Às minhas companheiras de quarto, Luciana e Telma, pela convivência, amizade, confiança, porque me fazem sentir querida - vocês são maravilhosas.

Às minhas vizinhas de quarto, Priscila e Naira, por compartilhar bons momentos e altas conversas.

Aos meus amigos Lucas e Mirko, pela amizade e carinho.

À Clarice, por ser minha amiga, e ter compartilhado o convívio familiar comigo.

À Patrícia Parenti, pela amizade e contribuição com sua arte.

Às minhas amigas peruanas, Eliana, Marita, Roxana e Mónica pela amizade e apoio desde o primeiro dia que cheguei ao Brasil.

Aos meus amigos e amigas das casas 12 e 13.

À Carô, Karina, Silvio, Gesline, Ernando, Rodrigo, Marcela, Marina, Bruno, Jamanta, Juliana, porque me fazem sentir em família.

Aos meus amigos em Peru, sempre ficando perto de mim, mesmo na distancia.

Às minhas amigas da Escola de Enfermagem, Bárbara, Andréia, Daniela e Lígia, é muito bom ficar perto de vocês.

Às minhas professoras de línguas Cecília, Lea e Gema, pela amizade e pelo incentivo, acompanhando minha trajetória.

Ao CNPq - Conselho Nacional de Desenvolvimento Científico e tecnológico, pelo incentivo financeiro.

A todos os que colaboraram na construção deste trabalho, seja na colaboração direta, ou dedicando sua amizade e apoio, muito obrigada. 
"Nunca ande pelo caminho traçado, pois ele conduz até onde os outros foram." (Grahan Bell)

"A vida só pode ser compreendida olhando-se para trás; mas só pode ser vivida olhando-se para frente." (Soren Kierkegaard)

"Para quem queira ver, há luz suficiente; para quem não quer, há bastante obscuridade." (Blaise Pascal) 


\section{RESUMO}

CATAÑO, R.C. Gravidez na adolescência: análise dos resultados nutricionais, obstétricos e neonatais. 104p. Dissertação (Mestrado) - Escola de Enfermagem de Ribeirão Preto. Universidade de São Paulo. Ribeirão Preto, 2007.

A Gravidez na adolescência é um serio problema de saúde pública. No Brasil, cerca de $20 \%$ dos partos são de mães adolescentes, sendo que a maioria delas não conta com condições financeiras nem emocionais para assumir a maternidade. Considerando que a condição clínica e nutricional da gestante pode interferir nos resultados obstétricos, perinatais e clínicos dos recém-nascidos (RNs), o objetivo deste estudo foi analisar o estado nutricional, os resultados obstétricos e os parâmetros clínicos dos RNs de mães adolescentes, atendidas para resolução da gravidez na MATER- Maternidade do Complexo Aeroporto, no ano de 2005. Trabalhou-se na abordagem quantitativa, retrospectiva, com o levantamento de 585 prontuários. As analises foram realizadas empregando-se o programa SPSS, versão 15.0. As variáveis qualitativas foram analisadas por freqüências simples e medidas de associação; para as quantitativas, foram calculadas medidas de tendência central e dispersão ou variabilidade; nas associações bivariadas, utilizaram-se tabelas de contingência, bem como o coeficientes $d$ de Sommer; na análise multivariavel, empregou-se o modelo de regressão logística múltipla por dicotomização dos desfechos de interesse. Encontrou-se que $46 \%$ das mães adolescentes finalizam a gravidez com baixo peso, $22,6 \%$ com sobrepeso e obesidade, e somente 36,4\% com peso normal. Quanto ao tipo de parto, a maior incidência foi de parto vaginal $(78,8 \%)$; também se observou que $93,5 \%$ das gravidezes foram a termo. Identificou-se 3,9\% dos RNs com baixo peso e $98,6 \%$ dos casos com Apgar normal ao quinto minuto. Nas associações, encontrou-se relação fraca, estatisticamente significativa, entre o peso da mãe e o perímetro cefálico, estatura e peso do RN $(\alpha=0,05)$. Na regressão logística multivariavel observou-se que o parto vaginal exerce um efeito protetor no risco de asfixia para um nível $\alpha=0,05$ no apgar do quinto minuto $(\mathrm{RC}=0,268)$, reduzindo o risco de asfixia em $70 \%$. Concluiu-se que a idade materna, de forma isolada, não determina o comportamento obstétrico. A orientação nutricional é um aspecto determinante para o desenvolvimento satisfatório de mãe e criança.

Palavras chave: gravidez na adolescência, estado nutricional, recém nascido. 


\begin{abstract}
CATAÑO, R.C. Teen pregnancy: analysis of the nutritional, obstetric and neonatal results. 104p. Composition (Mastering) - Escola de Enfermagem de Ribeirão Preto. Universidade de São Paulo. Ribeirão Preto, 2007.
\end{abstract}

Teen Pregnancy is a serious public health problem. In Brazil, 20\% of births come from adolescent mothers and majority of them don't have financial or emotional conditions to take on maternity. Considereing that the clinical and nutritional condition of the mother may impact the obstetric results, prenatal and health of newborns (NBs), the objective of this study was to analyze the nutritional, obstetric results and clinical conditions of the teen mothers and their NBs comming from pregnancy resolution at MATER - Maternidade do Complexo Aeroporto, in 2005. This research is based on a retrospective review of 585 medical records and the statistical analysis undertook the SPSS programme, version 15.0. The qualitative variables were presented in simple frequency and contingency tables; measures of central tendency and variability were used for quantitative variables. The bivariate association was described by the Sommer d coeficient and the multivariable analysis included logistic regression modelling. The result indicates that $46 \%$ of the teen pregnant mothers were below normal weight, 22,6\% were overweight and obese, and only $36,4 \%$ of the teen mothers were of normal weight. The prevaling method of birth was vaginal birth (78,8\%); furthermore, among the vaginal birth cases, 93,5\% of pregnancies went to full term. About 3,9\% of the newborns were below normal weight. $98,6 \%$ of the cases had normal Apgar at 5 minute. A weak and statistically significant correlation was found between the mothers' weight and the newborns' cephalic perimeter, height and weight $(\mathrm{p} \leq 0,05)$. It was observed that vaginal birth has a protecting effect on asfixia risk $(\alpha=0,1)$ at 5 minute apgar $(\mathrm{OR}=0,268)$ reducing it to $70 \%$. It was concluded that isolated maternal age doesn't determine obstetric behavior. Nutrition is a determining aspect for a mother and child's development.

Key-words: teen pregnancy, nutritional state, newborn. 


\section{RESUMEN}

CATAÑO, R.C. Embarazo en la adolescencia: análisis de los resultados nutricionales, obstétricos y neonatales. 104p. Disertación (Maestría) - Escuela de Enfermería de Ribeirão Preto. Universidad de São Paulo. Ribeirão Preto., 2007.

El embarazo en la adolescencia es un serio problema de salud pública. En el Brasil cerca del $20 \%$ de los partos son de madres adolescentes, siendo que la mayoría de ellas no cuenta con condiciones financieras ni emocionales para asumir una maternidad. Considerando que la condición clínica y nutricional de las gestante puede interferir en los resultados obstétricos, perinatales y de los recién nacidos (RNs), el objetivo de este estudio fue analizar el estado nutricional, os resultados obstétricos y los parámetros clínicos de los RNs de madres adolescentes, cuya atención del parto fue en la MATER, Maternidad del Complejo Aeropuerto, del año 2005. Se trabajó con un abordaje cuantitativo, retrospectiva, con el levantamiento de 585 historias clínicas. Los análisis fueron hechos en el programa SPSS versión 15.0. Para las variables cualitativas fueron realizadas frecuencias simples y medidas de asociación; para las cuantitativas se realizaron medidas de tendencia central y de dispersión o variabilidad; para las asociaciones bi variadas se utilizaron tablas de contingencia, así como el coeficiente de $d$ de sommer, en el análisis multivariada, se empleo el modelo de regresión logística múltiple por dicotomización. Se encontró que $46 \%$ de las madres adolescentes finalizaron el embarazazo con bajo peso, 22,6\% con sobrepeso y obesidad, y solamente $36,4 \%$ con peso normal. En relación al tipo de parto la prevalencia fue de parto vaginal (78,8\%), también se observó que 93,5\% de los embarazos fueron a término. Se identificó 3,9\% de RNs con bajo peso y en 98,6\% de los casos un Apgar normal al quinto minuto. En las asociaciones, se encontró una relación débil, estadísticamente significativa entre el peso de la madre y el perímetro cefálico, estatura y peso del $\mathrm{RN}(\alpha=0,05)$. En la regresión logística multivariada se observó que el parto vaginal ejerce un efecto protector en el riesgo de asfixia para un nivel ( $\alpha=$ $0,05)$, en el apgar de quinto minuto $(\mathrm{RC}=0,268)$ reduciendo el riesgo de asfixia en $70 \%$. Se concluye que la edad materna, de forma aislada, no determina el comportamiento obstétrico. La orientación nutricional es un aspecto determinante para el desarrollo satisfactorio de la madre y niño.

Palabras clave: embarazo en la adolescencia, estado nutricional, recién nacido. 


\section{SUMÁRIO}

APRESENTAÇÃO

\section{INTRODUÇÃO}

A escolha do objeto de estudo

\section{CONSTRUINDO O QUADRO TEORICO}

2.1 Gravidez na adolescência

2.2 Estado nutricional, resultados obstétricos de adolescentes grávidas e resultados clínicos de recém-nascidos

4 METODOLOGIA

4.1 Desenho do estudo …........................................................... 44

4.2 Local de estudo ...................................................................... 44

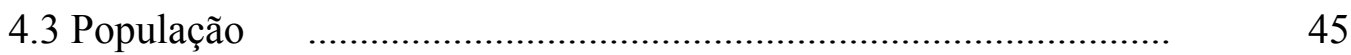

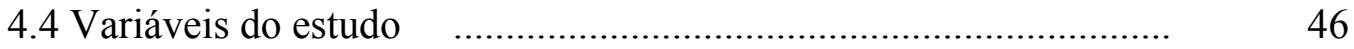

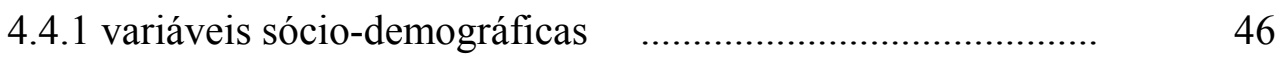

4.4.2 variáveis maternas - explicativas ou independientes $\quad$........ 46

4.4.3 variáveis do recém-nascido - resposta ou dependentes $\quad \ldots . . \quad 46$

4.5 Aspetos éticos $\quad$....................................................................... 51

4.6 Coleta de dados $\quad$........................................................................ $\quad 52$

4.7 Análise de dados ..........................................................................

5 RESULTADOS E DISCUÇÃO ……........................................ 55

5.1 Perfil sócio-demográfico das adolescentes $\quad$.................................. 56

5.2 Resultados Obstétricos $\quad$............................................................. 59

5.3 Caracterização dos recém-nascidos $\quad$........................................... 72 
6 CONCLUSÕES E LIMITES

7 REFERÊNCIAS

\section{APÊNDICE}

APÊNDICE A

\section{ANEXOS}

ANEXO A 


\section{LISTA DE TABELAS}

Tabela 1 - Distribuição quanto ao estado marital e escolaridade das adolescentes com resolução do parto na MATER. Ribeirão Preto SP 2005

Tabela 2 - Distribuição das mães adolescentes quanto ao controle pré-natal e paridade, MATER. Ribeirão Preto SP, 2005

Tabela 3 - Relação entre o peso, altura e idade gestacional de adolescentes de acordo com a curva de Rosso, MATER. Ribeirão Preto SP, 2005

Tabela 4 - Distribuição segundo o tipo de parto, idade gestacional, intercorrências maternas no parto e sangramento pós-parto de adolescentes, MATER. Ribeirão Preto SP, 2005

Tabela 5 - Distribuição das indicações de cesárea de adolescentes, MATER. Ribeirão Preto SP, 2005

Tabela 6 - Distribuição das intercorrências maternas no parto e puerpério de adolescentes, MATER. Ribeirão Preto SP, 2005

Tabela 7 - Distribuição das adolescentes quanto aos procedimentos durante o trabalho de parto, das adolescentes, MATER. Ribeirão Preto SP, 2005

Tabela 8 - Distribuição das características antropométricas e clínicas dos recém-nascidos de mães adolescentes, MATER. Ribeirão Preto SP, 2005

Tabela 9 - Distribuição dos procedimentos de atenção imediata aos recém-nascidos de mães adolescentes, MATER. Ribeirão Preto SP, 2005

Tabela 10 - Distribuição das intercorrências dos recém-nascidos de mães adolescentes, MATER. Ribeirão Preto SP, 2005

Tabela 11 - Distribuição dos recém-nascidos quanto ao tipo de parto, intercorrências maternas e Apgar. MATER. Ribeirão Preto SP, 2005

Tabela 12 - Associação entre o estado nutricional de mães adolescentes e parâmetros clínicos dos recém nascidos, MATER. Ribeirão Preto SP, 2005 
Tabela 13 - Distribuição dos recém-nascidos quanto aos escores de Apgar de primeiro minuto e os preditores maternos. MATER. Ribeirão Preto SP, 2005

Tabela 14 - Distribuição dos recém-nascidos quanto aos escores de Apgar do quinto minuto e os preditores maternos. MATER. Ribeirão Preto SP, 2005 
Apresentação 
Desde o início de minha formação e no desempenho profissional como enfermeira obstétrica, os problemas relacionados à adolescência e gravidez sempre motivaram o desejo de pesquisar esse tema, com o intuito de buscar respostas para algumas, perguntas relacionadas a essa fase da vida.

Durante o ano do meu internato no Hospital Daniel Alcides Carrión, em Lima Peru, desenvolvendo assistência no serviço de centro obstétrico e na emergência de ginecologia e obstetrícia, comecei a me interessar pela pesquisa na área de saúde da mulher, especificamente com a gravidez na adolescência.

Trabalhando, posteriormente, em clínicas de atenção materno-infantil, vinculadas ao seguro saúde, com melhor situação econômica, observei que o número de adolescentes grávidas era bastante reduzido. Além disso, observava que maior nível socioeconômico estava relacionado a melhores resultados obstétricos. Entre as adolescentes grávidas, atendidas em hospital público, com baixo recurso econômico, com muitos medos e muitas delas sem ajuda da família, ou do parceiro, os resultados obstétricos e perinatais eram piores.

Essas observações foram fortalecendo meu desejo de aprofundar os estudos sobre a gravidez na adolescência, pois, além dos riscos que representam à saúde do binômio mãe-filho, o comportamento das adolescentes durante esse período pode interferir no futuro de ambos.

É amplamente divulgado que as adolescentes grávidas podem apresentar sérios riscos devido à sua imaturidade psicológica e física, falta de controle pré-natal, ou início tardio, e falta de apoio familiar. Ao mesmo tempo, têm dificuldades para concluir seus estudos, piores oportunidades de emprego e instabilidade financeira, continuando com a cadeia de desigualdade social. 
Ao lado das potenciais repercussões existenciais, associadas à gravidez na adolescência, há indícios, no plano biológico-social, de maior concentração de agravos à saúde materna, bem como complicações perinatais, particularmente entre adolescentes mais jovens. Goldenberg; Figueiredo; Silva (2005) relatam que, dentre as complicações maternas e neonatais mais freqüentes, estão o baixo ganho de peso materno, a desproporção céfalopélvica, a pré-eclâmpsia, a prematuridade, baixo peso ao nascer e índice de Apgar baixo no quinto minuto.

Muitas adolescentes, no entanto têm gravidez normal, um parto sem complicações e filhos saudáveis; mas é amplamente divulgado que pode haver sérias complicações clínicas, obstétricas, perinatais e emocionais.

O problema da gravidez na adolescência não é um caso isolado, é problema que alcança cifras alarmantes e, no Brasil, a cada ano, cerca de $20 \%$ das crianças que nascem são filhos de mães adolescentes, sendo que a maioria dessas adolescentes não tem condições financeiras nem emocionais para assumir a maternidade. A Organização Mundial de Saúde considera a gravidez na adolescência como de alto risco, devido às repercussões sobre a saúde da mãe e do bebê (REDE FEMINISTA DE SAÚDE, 1999).

As desigualdades sociais, políticas e econômicas no Brasil têm influenciado a dinâmica familiar e aumento do número de crianças e adolescentes em situação de risco pessoal e social.

As autoridades de saúde pública no mundo têm se preocupado com a gravidez na adolescência, considerando o número alarmante de casos e as repercussões que a gestação pode determinar sobre a jovem mãe, mas as ações planejadas e implementadas não têm sido suficientes para o enfrentamento dessa ocorrência. Entre os pro- 
blemas que merecem ser considerados, destacam-se as carências nutricionais na gestação.

O estado nutricional da mãe tem efeito determinante no crescimento do feto e no peso do recém-nascido (RN). Existem evidências concretas de que o ganho ponderal, durante a gestação, serve de diagnóstico para o peso do $\mathrm{RN}$ ao nascer, que pode ser afetado pelo estado nutricional e estatura da mãe antes da gravidez (IDENTIFICACIÓN, 1999).

Isso é importante do ponto de vista de saúde pública, já que o peso ao nascer é um dos parâmetros que mais se relaciona com a sobrevivência, crescimento e desenvolvimento mental do RN.

Considerando que as condições clínicas e o estado nutricional das gestantes podem interferir nos resultados clínicos dos recém-nascidos, este estudo buscará evidenciar as variáveis relacionadas à problemática. É possível que a adolescente grávida dependa do estado nutricional dentro dos parâmetros da normalidade para obter resultados obstétricos e perinatais satisfatórios (parto normal sem intercorrência, recém-nascido a termo, com peso adequado para a idade gestacional, em boas condições de vitalidade). 
Introdução 


\subsection{A escolha do objeto de estudo}

O processo histórico e social nos mostra que a prática de saúde reprodutiva é uma ação relativamente recente. Iniciou-se em 1968, na Conferência Internacional sobre Direitos Humanos, ocorrida em Teerã, onde a reprodução humana foi objeto de discussão. No entanto, essa preocupação foi percebida mais como uma forma de pressionar os países menos desenvolvidos a adotarem políticas de controle demográfico do que uma tentativa de defender o direito reprodutivo dos indivíduos (VIEIRA, 2003).

Durante séculos, a função da mulher era reproduzir; esse sentido se inverte nos anos 50, passando a haver esforço por limitar a quantidade de filhos por mulher, especialmente nos setores mais pobres (VILLELA; ARILHA, 2003).

Segundo Vieira (2003), do ponto de vista dos direitos humanos, os direitos reprodutivos foram definitivamente incorporados com a Conferência Internacional de População e Desenvolvimento (Cairo Egipto) e a IV Conferência Mundial sobre a Mulher, em meados da década de 1990, quando diversos países concordaram que suas políticas públicas iriam se pautar pelos acordos.

Assim, nos últimos anos observou-se importantes avanços no sentido de ampliar e melhorar os serviços de saúde integral à mulher. No entanto, continuam existindo sérios problemas na saúde reprodutiva, como altas taxas de morbimortalidade materna, gravidez na adolescência, gravidez não desejada e abortos clandestinos.

Cerca de $10 \%$ dos abortos no mundo são realizados em meninas entre 15 e 19 anos. Calcula-se que 55 mil abortos inseguros no mundo são praticados a cada dia, e que $95 \%$ desse total ocorram em países em desenvolvimento. Na América Latina, o aborto malsucedido é motivo de freqüentes internações, sendo estimado que uma a 
cada 10 mulheres com menos de 20 anos seja hospitalizada por esse problema (REDE FEMINISTA DE SAÚDE, 1999).

A Pesquisa Nacional sobre Demografia e Saúde, em 1996, mostrou que 18\% das adolescentes brasileiras já tinham tido pelo menos um filho, ou estavam grávidas, sendo que $24 \%$ eram de áreas rurais e $17 \%$ de áreas urbanas. Outro dado alarmante foi encontrar que metade das jovens entre 14 e 19 anos sem nenhum ano de escolaridade já tinham sido mães (REDE FEMINISTA DE SAÚDE, 1999).

Ainda na $57^{\circ}$ Reunião Mundial de Saúde, foi recomendado que a saúde reprodutiva e sexual fizesse parte dos processos de planejamento e financiamento dos sistemas de saúde; além disso, países membros deveriam aplicar estratégias que assegurassem a saúde reprodutiva e sexual para adolescentes, mães e recém-nascidos, para alcançar o desenvolvimento do Milênio das Nações Unidas (ORGANIZAÇÃO MUNDIAL DA SAÚDE. OMS, 2004).

Os adolescentes representam quase $20 \%$ da população mundial; estima-se mais de um bilhão de pessoas entre 10 e 19 anos. O problema da gravidez na adolescência alcança grandes proporções. Calcula-se que mais de 14 milhões de adolescentes dão à luz cada ano no mundo, e problemas sociais como o aborto também têm aumentado.

No Brasil, os adolescentes representam $21 \%$ da população total. Encontramse $10 \%$ na faixa de $10-14$ anos e $11 \%$ entre 15 - 19 anos, com o número total de 35302872 . Os adolescentes de sexo masculino representam 50,4\% desse total e as adolescentes de sexo feminino representam $49,5 \%$, sendo que adolescentes de sexo masculino são 17792647 e adolescentes do sexo feminino 17510224 (INSTITUTO BRASILEIRO DE GEOGRAFIA E ESTATÍSTICA. IBGE, 2000). 
Em 2002, 17\% de adolescentes não tinham facilidades para receber serviços de saúde e, no Brasil, quase não existem serviços de saúde específicos para atender as necessidades dos adolescentes e jovens, grupo que se encontra mais vulneráveis à violência, à gravidez, às doenças sexualmente transmissíveis (DTS) e à AIDS (FUNDO DAS NAÇÕES UNIDAS PARA A INFÂNCIA. UNICEF, 2003).

Nas últimas décadas, estudos estão demonstrando que os adolescentes de ambos os sexos iniciam relações sexuais mais cedo, sendo que a idade média da primeira experiência sexual é de 16 anos para as meninas. No ano 2002, 32,8\% dos adolescentes brasileiros entre 12 e 17 anos já haviam tido relações sexuais, sendo que 39\% eram moças (UNICEF, 2002).

Estudo feito pelo programa de Saúde do Adolescente do Estado de São Paulo constatou que, em $28 \%$ dos casos, as adolescentes engravidam nos três primeiros meses após o início da atividade sexual (BRASIL, 2003).

A gravidez é processo fisiológico na vida da mulher, mas requer cuidados e supervisão especializados pelas diferentes áreas de saúde, para diminuir os riscos e otimizar os resultados maternos e perinatais. O objetivo do controle de toda gravidez é obter um recém-nascido sadio, e, para a mulher, o mínimo de traumas. O peso ao nascer, a idade gestacional, a asfixia neonatal e as condições do nascimento são objeto de muito interesse para a prática obstétrica, pois desses resultados, depende a qualidade de vida do binômio mãe-filho.

A adolescência e a gravidez são dois momentos da vida em que uma boa alimentação pode determinar a qualidade de vida dos indivíduos envolvidos. Os requerimentos nutricionais necessários ao desenvolvimento da adolescente e da mulher grávida, em separado, são bem conhecidos, mas há necessidade de estudos que inves- 
tiguem a relação entre essas duas ocorrências e a associação entre elas. A gravidez na adolescência, portanto, é um momento em que o desenvolvimento de duas pessoas pode ser afetado.

No período da gravidez e lactação, as adolescentes requerem cuidados e medidas de suporte especiais, devido aos riscos nutricionais, clínicos e psicossociais. A evolução da gravidez na adolescência e o crescimento fetal são alterados pelos maiores riscos de desnutrição, deficiências nutricionais, uso de drogas e infecções como DST/HIV/AIDS, mostrando aumento nos índices de prematuridade, baixo peso ao nascer e desnutrição pós-natal (EISENTEIN, 2000).

Os dados estatísticos em relação à gravidez na adolescência são alarmantes: a principal causa de intervenção no sistema público de saúde em meninas de 10 a 19 anos de idade é a gravidez, parto e pós-parto, em todas as Regiões do País, sendo que $79,5 \%$ na Região Norte, $81,1 \%$ no Nordeste, $80,9 \%$ no Sudeste, $77,6 \%$ no Sul, 80,2\% no Centro-Oeste (REDE FEMINISTA DE SAÚDE, 1999).

No Estado de São Paulo, entre 2000 e 2002, do total de nascidos vivos de mães entre 10 e 14 anos foi de 11241 e entre 15 e 19 anos foi de 357 091, perfazendo um total de 368332 recém-nascidos de mães adolescentes em um período de três anos (BRASIL, 2005).

Esses dados se tornam mais relevantes quando consideramos que o Estado de São Paulo possui as menores taxas de gravidez na adolescência em relação a outras regiões brasileiras, havendo aumento de gestações em adolescentes de baixo nível de escolaridade (OLIVEIRA, 1999).

Considerando o plano reprodutivo, a maioria das adolescentes chega à maturidade sexual antes de atingir a maturidade social, emocional e antes de conseguir 
independência econômica. Dentre as múltiplas determinações, a erotização do adolescente, promovida pela mídia, estimula a iniciação sexual precoce que, na ausência do domínio das práticas contraceptivas, pode resultar em gravidez não desejada. Essa gravidez é agravante em seu complexo quadro existencial, comprometendo seu futuro profissional, dificultando o retorno aos estudos e limitando as oportunidades de trabalho (GOLDENBERG; FIGUEIREDO; SILVA, 2005).

Parenti (2002), em estudo sistemático de revisão da literatura, identificou que os autores enfocam a maternidade na adolescência como risco biológico e/ou social, com conseqüências para a vida da adolescente e seu filho. A autora ressalta que, independentemente de como se apresenta, a gravidez na adolescência é multicausal, e a justificativa para a sua existência está vinculada a aspectos socioeconômicos, educacionais, religiosos, espirituais, jurídicos e culturais.

Considera-se que a mãe adolescente está sujeita a fracassar em cumprir suas funções, permanecer na escola, limitar o número de filhos, adquirir independência financeira e estabelecer uma família. Entre as adolescentes, há maior freqüência de analfabetismo, condição social instável, observa-se mães sem ajuda do parceiro e tabagistas. (MARIOTONI; BARROS FILHO, 2000).

A adolescente grávida tem maior risco de ter filhos de baixo peso ao nascer e pré-termo e, pelo fato de não ter completado seu desenvolvimento, tem mais riscos de complicações, como desproporção cefalepélvica, sofrimento fetal agudo, distócia de dilatação e asfixia neonatal, refletindo-se em altas taxas de cesáreas e baixas pontuações na avaliação do Apgar, tendo, como conseqüência, filho de alto risco neonatal (YAZLLE, 2002). 
O baixo peso ao nascer é considerado um dos indicadores mais significativos para avaliar a qualidade de vida de determinada população; pois é o enlace para uma cadeia de patologias do período neonatal e problemas de saúde no primeiro ano de vida. A incidência do baixo peso gera incremento na demanda de atenção à saúde, causando transtornos familiares e sobrecarga do orçamento para atenção nos serviços de cuidados intensivos e neonatais especiais (IDENTIFICACIÓN, 1999).

Um recém-nascido de baixo peso, prematuro, ou com complicações neurológicas ao nascer, muitas vezes com um ou mais problemas associados, representa não só problema para a mãe, mas também para a sociedade, pela maior probabilidade de aumento do tempo de internação e retornos em unidades de saúde, gerando um problema econômico e comprometendo a qualidade de vida materna e da criança.

Nesse sentido, é que aqui se propõe a analisar o estado nutricional, os resultados obstétricos e os parâmetros clínicos dos recém-nascidos de mães adolescentes, com vistas a promover cuidado pré-natal que responda às necessidades desse grupo específico. 
Marco teórico 


\subsection{Gravidez na adolescência}

Etimologicamente a palavra latina adolescere tem o sentido de crescer e o termo adolescente, tem sido empregado por séculos não como sinônimo de jovem, mas sim no sentido de designar a pessoa que se encontra numa etapa cronológico temporal entre a infância e a vida adulta.

Existem diferentes critérios para delimitar a adolescência; em gera, a base de referência é o aparecimento inicial das características secundárias de maturação sexual e os processos sociais e psicológicos, como transição de um estado de dependência para outro de independência. Os limites da adolescência, segundo a OMS, são entre 10 e 19 anos.

A adolescência é o período no qual se distinguem dois momentos: puberdade e adolescência, cada uma delas caracterizada por determinados processos fisiológicos. A puberdade caracteriza-se por mudanças funcionais e corporais, aparição dos diferentes caracteres secundários, ocorrência da menarca para as mulheres e, conseqüentemente, início da capacidade reprodutiva (ISSLER, 2001).

Dentro desse processo dinâmico e contínuo, não se pode tomar a adolescência como simples adaptação e transformação corporais. É período muito importante no ciclo existencial da pessoa, momento de grandes conflitos e crises, o início de tomada de posição em diferentes âmbitos, que se vêm influenciados de maneira favorável ou desfavorável pelo meio ambiente ou pelo contexto social no qual o indivíduo se desenvolve (EISENTEIN et al., 2000).

Esse conjunto de situações na vida da adolescente marca seu autoconhecimento, os sentimentos de auto-estima; como também os impulsos sexuais se modificam de acordo com seu desenvolvimento físico. O início de sua capacidade de pro- 
criação, e os diferentes papéis: laboral, familiar e sexual auxiliarão na formação de sua identidade. Em relação ao gênero, a mulher adolescente se encontra mais vulnerável aos problemas de saúde reprodutiva, encontrando-se no grupo de risco (RUZANY, 2000).

A maior parte das adolescentes desconhece aspectos relacionados à saúde reprodutiva e saúde sexual e tais informações, geralmente, são obtidas com outros adolescentes, companheiros e amigos, tendo como conseqüência aumento de doenças de transmissão sexual e gestações não desejadas (FURLAM et al., 2003).

Médicos, psicólogos, pedagogos e assistentes sociais concordam que a liberalização da sexualidade, a falta de informação, a urbanização acelerada, separação familiar, condições precárias de vida e a influência dos meios de comunicação são os maiores responsáveis pelo aumento do número de adolescentes grávidas (PAULICS; FERRON, 2006).

A gravidez na adolescência acontece em todas as classes sociais, mas a maior incidência é em populações mais carentes. A ausência de orientação sexual específica, o rigor religioso, tabus morais internos da família e falta de atividades de lazer contribuem para o aumento do problema. A maioria das adolescentes abandona os estudos, algumas fogem de casa e interrompem seu processo de socialização (PAULICS; FERRON, 2006).

A gestação em idades extremas da vida reprodutiva, menor de 20 anos e maior de 35 anos, estão associadas à maior freqüência de resultados perinatais adversos. Segundo Azevedo et al. (2002) esses resultados traduzem mais claramente as condições sociais e de saúde do que propriamente a idade. 
As desigualdades na saúde da população são dadas pelos diferentes gradientes sociais, fatores econômicos, educação, ambiente e ocupação. Assim, conforme referem Szwarcwald et al. (1999), as condições de vida modificam as diferentes taxas de morbidade e mortalidade na população brasileira.

Os hábitos, como o uso de álcool, drogas, fumo, doenças de transmissão sexual, desnutrição, anemia, abuso físico e sexual, podem, com freqüência, aumentar a morbidade tanto para mãe como para o filho. Goldenberg; Figueiredo; Silva (2005) referem que vários autores, questionando a importância da idade, ressaltam que as complicações relativas aos desfechos da gravidez na adolescência se associam às condições sociais de existência, relacionadas ao nível de escolaridade, estado civil, apoio familiar e, sobretudo, com o adequado acompanhamento pré-natal.

A jovem mulher tem que construir sua identidade, elaborar seus projetos de vida, deixar o espaço doméstico e se inserir nos espaços públicos, principalmente pela necessidade de ter um trabalho que garanta sua sobrevivência. Além dessas dificuldades, ela tem que administrar emoções e entender as mudanças que acontecem em seu corpo, uma sobrecarga de necessidades fisiológicas e psicológicas, e, no caso de gravidez precoce, pode acarretar o que se chama risco psicossocial (PAULICS; FERRON, 2006).

Ressalta-se, entretanto, que, durante muitos anos, ter filhos em idade precoce era algo comum no cotidiano da nossa sociedade. Atualmente, esse conceito tem mudado, pois essa ocorrência está relacionada a riscos sociais, psicológicos e biológicos (CRUZ, 2002).

Nas civilizações antigas, as meninas com sinais de puberdade já eram consideradas aptas para o casamento. Naquela época, a capacidade reprodutiva estava as- 
sociada ao início da juventude, sendo que, quanto maior a quantidade de filhos, maior mérito da família. Fatores religiosos, em especial da Igreja Católica, tinham muito poder em questões de reprodução e sexualidade, na proibição de métodos anticoncepcionais, contribuindo para a ocorrência de famílias com 12, 15 ou 20 filhos. Ninguém questionava a capacidade psicológica e biológica daquelas jovens mães em parir, cuidar e educar seus filhos (FERNANDES, 2002).

Segundo Salazar et al. (2003), a imaturidade biológica dos órgãos sexuais da menina impede a correta transferência de nutrientes ao feto, conseqüentemente afetando a nidação, o metabolismo e a adaptação cardiovascular materna. Por essa razão, alguns pesquisadores discutem que a atenção nutricional às adolescentes grávidas constitui um fator importante na redução da incidência de recém-nascidos de baixo peso.

Estudo mostrou que, em relação à idade cronológica (mãe adolescente), quando outras variáveis foram controladas, a idade materna de forma isolada não foi responsável pelo baixo peso ao nascer, não houve associação estatisticamente significativa entre baixo peso ao nascimento com a idade da mãe (COSTA, 1999).

A gravidez na adolescência tem numerosos riscos: muitas adolescentes morrem no mundo por causas relacionadas à gravidez, e essas são influenciadas pelas condições econômicas, sociais e culturais, mas a atenção oportuna da equipe de saúde pode diminuir o prejuízo de maneira significativa. A adolescente grávida deve ter atenção especializada, já que ela tem maior probabilidade de morrer no parto em relação a uma mulher com mais de vinte anos, e se a mãe adolescente tem menos de 15 anos, esse risco aumenta 5 vezes (CRUZ, 2002). 
As condições sociais e econômicas potencializam ainda mais a estrutura emocional da mãe adolescente que, às vezes, não conta com o apoio do pai da criança e da própria família (GAMA, 2001).

As complicações neonatais e maternas mais freqüentes, relativas à gravidez na adolescência, são o baixo ganho de peso materno, a desproporção cefalopélvica, hipertensão arterial (eclâmpsia), baixo peso ao nascer, prematuridade, o índice de Apgar baixo, menor do que sete no quinto minuto (GOLDENBERG; FIGUEIREDO; SILVA, 2005).

\subsection{Estado nutricional, resultados obstétricos de adolescentes grávidas e resultados clínicos de recém-nascidos}

A nutrição durante a gravidez é muito importante e, muitas vezes influenciada pelas crenças que podem interferir negativamente com a saúde da mãe e do feto. Portanto, a educação sobre os alimentos que a gestante deve consumir e os controles de ganho de peso durante o pré-natal são importantes para o melhor desenvolvimento e crescimento do feto.

O controle nutricional da mulher grávida tem como objetivo estabelecer seu estado nutricional e identificar fatores de risco, possibilitando medidas terapêuticas e profiláticas para corrigir e planejar a educação nutricional. As avaliações nutricionais devem ser realizadas continuamente e ao longo da gravidez, de forma a possibilitar a detecção de hábitos desfavoráveis (AZEVEDO; SAMPAIO, 2003).

O estado nutricional materno tem forte influência no desenvolvimento fetal. O peso pré-gravídico insuficiente, a baixa estatura da mãe, o exagerado ou escasso 
incremento de peso durante a gravidez são associados a maus resultados perinatais; assim, o controle de peso materno é um dos parâmetros mais importantes durante o controle pré-natal (SCHWARCZ, 2001).

As medidas utilizadas na avaliação do estado nutricional materno são os indicadores antropométricos que vão identificar as mulheres com risco de complicações gestacionais e de dar à luz a criança com baixo peso (RIBEIRO et al., 2002).

A adequada interpretação do Índice de Massa Corporal (IMC), junto com a atenção nutricional, constitui indicador importante no prognóstico de crescimento fetal e é ferramenta para melhorar a qualidade de vida dos recém-nascidos de mães adolescentes (SALAZAR et al., 2003).

Para avaliar o estado nutricional, temos a curva proposta por Rosso, que tem como objetivo avaliar o ganho de peso, baseado na adequação de peso/altura, de acordo com a idade gestacional, possibilitando diagnóstico nutricional na primeira consulta e monitoramento do ganho ponderal na gestação, instrumento de fácil execução e de baixo custo. Nessa avaliação, é recomendado que todas as mulheres alcancem, no final na gestação, $120 \%$ do padrão peso/estatura na curva (RIBEIRO et al., 2002).

Durante o período de gravidez, a mulher necessita de energia adicional por causa do crescimento do feto, dos tecidos maternos, bem como para o consumo do feto. Em uma gravidez eutrófica, o ganho ponderal é em torno de $12,5 \mathrm{~kg}$, e o recémnascido com peso ao nascimento superior a $3 \mathrm{~kg}$. A restrição alimentar nesse período pode provocar conseqüências negativas, pois o crescimento fetal ótimo ocorre quando a grávida é capaz de acumular reservas corporais extras (AZEVEDO; SAMPAIO, 2003). 
Segundo Gama (2001), a imaturidade do sistema reprodutivo, o inadequado ganho de peso, os fatores socioculturais como pobreza, marginalidade, baixos níveis de instrução, a falta de cuidados pré-natais, combinados ao estilo de vida da adolescente, têm sido associados à ocorrência de recém-nascidos de baixo peso.

O crescimento fetal está relacionado às características maternas, tais como antropometria materna, peso pré-gravídico, nutrição e ganho de peso durante o período da gravidez (GRANDI, 2003).

Se a gestante conhece seu peso habitual pré-gravídico, o aumento será controlado, utilizando-se como padrão de referência a idade gestacional em semanas e o ganho de peso. A variação do ganho de peso oscila entre 6 e 16 quilos até finalizar a gestação, considerando que o máximo incremento fica entre a $12^{\mathrm{a}}$ a $24^{\mathrm{a}}$ semana de amenorréia. Deve-se calcular a idade gestacional e depois subtrair o peso prégravídico do peso atual, obtendo-se, assim o incremento de peso para determinada idade gestacional (SCHWARCZ et al., 2001).

Quando a gestante desconhece seu peso habitual, o controle será por meio dos incrementos semanais, aceitando-se como normal o aumento de $400 \mathrm{~g}$ semanais no segundo trimestre e de $300 \mathrm{~g}$ semanais no terceiro trimestre (SCHAWARCZ et al., 2001).

O peso pré-gestacional é medida do estado nutricional materno. O ganho de peso total durante a gravidez é o resultado do processo fisiológico e a mulher com baixa ingestão de nutrientes requer incremento de peso superior a 5 quilos a mais do que o valor médio. Esse peso está distribuído entre o feto, placenta, líquido amniótico, aumento de volume sangüíneo, crescimento de útero e mamas. As mulheres com peso abaixo do ideal têm maior probabilidade de ter filhos com baixo peso e esse 
indicador é importante porque muitas adolescentes iniciam a gravidez com déficit nutricional (IDENTIFICACIÓN, 1999).

O estado nutricional da mãe está relacionado a grandes fatores, que são: a) disponibilidade de alimentos, que está determinada fundamentalmente pela condição socioeconômica; b) aproveitamento dos alimentos, ou seja, capacidade do indivíduo de cumprir com todos os processos fisiológicos normais; c) consumo de alimentos, considerando-se os hábitos, e os outros dois fatores antes mencionados (IDENTIFICACIÓN, 1999).

Na 53 ${ }^{\mathrm{a}}$, reunião da Comissão de Direitos Humanos indicou-se que a boa alimentação é parte de um nível de vida adequado. As carências alimentares de forma quantitativa e qualitativa na mulher têm significado muito importante, pelas conseqüências diretas sobre o crescimento e desenvolvimento do feto, afetando de maneira previsível o futuro da espécie humana, considerando quatro pontos básicos, que são: disponibilidade de alimentos, acessibilidade, qualidade dos alimentos e cultura alimentar (GOMEZ; ANZARDO, 2003).

Grandi (2003), analisando o ganho de peso gestacional com os riscos ao nascer, demonstrou que o inadequado ganho de peso durante a gravidez é parâmetro referencial para baixo peso ao nascer, pequeno para idade gestacional e prematuridade. O problema mais importante detectado neste estudo foi a desnutrição crônica que começou, em muitas mulheres, na vida intra-uterina e que continuou na vida reprodutiva, gerando carências nutricionais e processos infecciosos agudos. O autor, ainda, cita que condições socioeconômicas desfavoráveis e restrição no tamanho da pélvis podem afetar o crescimento fetal e a duração da gestação. Outro problema nutricional identificado nesse estudo foi o sobrepeso. 
Segundo Furlan et al. (2003), a gravidez não planejada pode criar ou agravar os distúrbios nutricionais. Na pesquisa sobre a relação do estado nutricional da adolescente grávida, tipo de parto e o peso do RN, os autores identificaram que $34 \%$ das gestantes adolescentes já apresentavam desvios do ideal de peso quando iniciaram a gravidez.

Estudo, realizado por Salazar et al. (2003), mostrou que o índice de massa corporal tem importante influência no crescimento fetal e no peso ao nascer. As adolescentes que iniciaram a gestação com IMC $<19.8$ (desnutridas), tiveram fetos e recém nascidos com dimensões corporais abaixo que o normal.

O baixo peso ao nascer (inferior a $2500 \mathrm{~g}$ ) é determinante do estado de saúde e sobrevivência infantil, pois há maior probabilidade de morte, e esses problemas repercutem na vida adulta, com elevação do risco de problemas cardiovasculares e metabólicos (GODFREY, 2000).

O baixo peso ao nascer tem sido associado a diversos fatores, tais como:

1) consumo de álcool, tabaco, drogas: estudos têm demonstrado que os filhos de mulheres fumantes pesam de 200 a 300 gramas menos em relação aos filhos de mães não fumantes;

2) intervalos curtos entre uma gravidez e outra - durante a gravidez e na lactação a mãe diminui suas reservas biológicas e nutricionais, motivo pelo qual ela tem que se recuperar e se preparar para outra gravidez;

3) A idade materna: os riscos aumentam quando a grávida é adolescente ou tem mais de 35 anos; 
4) o estado nutricional materno; que é condicionado pela disponibilidade de alimentos, aproveitamento biológico e o consumo dos alimentos (IDENTIFICACION, 1999).

O peso materno é medida mais fácil de obtenção e que pode ajudar na detecção de anormalidades na gravidez e na previsão do peso do recém-nascido. Faúndes; Parpinelli; Pereira, (2000) lembram que esses dados têm forte comprovação na literatura científica mundial, e que praticamente todo cartão de pré-natal tem o peso materno registrado em cada consulta.

A gravidez na adolescência tem sido citada entre os fatores de risco para o baixo peso ao nascer, porém, pesquisas mostram resultados contraditórios. No Brasil, há variações regionais entre 10 e $23,3 \%$ de baixo peso entre os recém-nascidos de mães adolescentes (MARIOTONI; BARROS FILHO, 2000).

A criança de baixo peso ao nascer não é uma casualidade do destino. Esse fato está determinado por condições sociais e econômicas, nutricionais, morbidade materna e fetal, e deficiência ou falta de controle durante a gravidez (TAKITO, 2005).

A prevalência do baixo peso ao nascer é atribuída à idade da mãe (imaturidade biológica), junto com outros fatores externos, como as condições psicossociais que podem estar atuando negativamente, já que o aspecto biológico não pode ser avaliado isoladamente (MARIOTONI; BARROS, 2000).

O recém-nascido pré-termo tem grandes riscos de adaptações à vida extrauterina devido à imaturidade anatômica e fisiológica e do processo da terapêutica, está mais exposto a riscos e danos e pode apresentar uma série de complicações após 
o nascimento, como hipóxia, distúrbios respiratórios, metabólicos, infecções entre outras (VASCONCELOS, 2001).

O nascimento de um pré-termo com menos de 36 semanas de gestação responde por $70 \%$ das mortes neonatais, sendo um dos principais problemas da perinatologia. A prematuridade, associada ao baixo peso ao nascer, tende a ser considerada uma questão de muita importância em razão de sua prevalência - em torno de $10 \%$ em quase todo o mundo. Com a finalidade de diminuir esses índices, têm sido pesquisados fatores de risco para prematuridade, tais como idade materna (abaixo dos vinte anos), condições sociodemográficos, condições de saúde da grávida, grau de pobreza, uso de cigarro, álcool, drogas e inadequação ou falta de controle pré-natal. No entanto, tais fatores respondem por aproximadamente $30 \%$ dos nascimentos prematuros, o que leva a pesquisa de fatores de risco para a prematuridade em direção aos aspectos psicossociais, dentre outros (ZUCCHI, 1999)

A questão da prematuridade é relevante não só pelos índices de mortalidade a ela associados, mas também pela qualidade de vida restrita de muitos dos que a ela sobrevivem. Embora os avanços tecnológicos permitam a sobrevivência de crianças cada vez menores (em termos tanto de idade gestacional, como de peso ao nascer), as seqüelas da prematuridade podem ser graves e penosas, envolvendo tanto a criança como a família (ZUCCHI, 1999).

Apesar dos importantes avanços nos estudos relacionados ao parto prematuro e à sua prevenção, a taxa de prematuridade se mantém constantemente elevada em alguns locais, tornando-se imprescindível a melhoria na assistência pré-natal como uma das estratégias de identificar os casos de maior risco, a fim de diagnosticar os 
estágios iniciais do trabalho de parto prematuro. Apesar de toda tecnologia disponível, em alguns casos não se impedirá o nascimento prematuro, por isso se deve também propiciar melhores condições de nascimento (BITTAR, 2001).

Quanto menor é o desenvolvimento do recém-nascido, maior seu risco de apresentar insuficiência no crescimento, atrasos no desenvolvimento psicomotor, repercussões na capacidade cognitiva, e possivelmente até a vida adulta. O recémnascido pré-termo tem limitações fisiológicas, o ritmo de crescimento é restrito ou acelerado, tanto intra como extra-uterino com importantes repercussões na vida da criança (CAMELO JUNIOR, 2005).

A chance de morte neonatal de uma criança com menos de 37 semanas de gestação é maior quanto mais precoce é ela, e tem 40 vezes mais probabilidade de morrer do que uma criança a termo. Assim, uma criança com peso inferior a $1500 \mathrm{~g}$ tem riscos de complicações neurológicas 20 vezes maior em relação ao recémnascido a termo, e maior número de internações durante o primeiro ano de vida, até 3 a 4 vezes mais freqüente, o que demonstra o impacto social e econômico que representa (ZUCCHI, 1999).

O método mais comumente empregado para avaliar o ajuste imediato do recém-nascido à vida extra-uterina é o sistema de escore do Apgar, obtido na observação da freqüência cardíaca, do esforço respiratório, do tono muscular, da irritabilidade reflexa e da coloração da pele do RN. Cada item recebe a pontuação que varia entre zero (0), 1 ou 2. As avaliações de todas as cinco categorias são feitas com 1 e 5 minutos após o nascimento e são repetidas até que a condição da criança se estabilize (RIBEIRO, 2004). 
O Apgar no primeiro minuto é considerado como diagnóstico da situação presente, e o do quinto minuto é considerado como importante fator de prognóstico da saúde neurológica do recém-nascido. Cabe dizer que uma nota baixa no primeiro minuto não é tão importante, desde que o recém-nascido seja atendido prontamente e a pontuação do quinto minuto seja maior que sete (RIBEIRO, 2004).

As pontuações de 0 a 3 representam sofrimento grave, escores de 4 a 6 significam dificuldade moderada, e de 7 a 10 indicam ausência de dificuldade de adaptação à vida extra-uterina. O índice de Apgar é afetado pelo grau de prematuridade, sedação ou analgesia materna e distúrbios neuromusculares (WONG, 1999).

O índice de Apgar baixo é sinal de pouca vitalidade, que pode decorrer da falta de oxigênio no cérebro, ou anoxia. A asfixia entre 30 e 60 segundos pode lesionar irreversivelmente o cérebro do recém-nascido, causando muitos problemas neuropsicomotores como, por exemplo: déficit na sucção e deglutição, problemas de respiração, paralisia cerebral, autismo, dislexia e problemas de aprendizagem, que podem comprometer toda a vida (RIBEIRO et AL., 2004).

A asfixia neonatal é causa de índice de Apgar baixo e dano neurológico, sendo que o feto reage à asfixia neonatal com muitas respostas fisiológicas, hormonais e celulares. Dentre as fisiológicas, as mais importantes são bradicardia, aumento da pressão arterial, seguido pela diminuição dessa na redistribuirão do fluxo cerebral e depressão do sistema nervoso central. As respostas hormonais e celulares podem ser detectadas como variações normais de diferentes elementos bioquímicos como catecolaminas, argina-vasopresina, entre outros (CUNHA, 2004).

Gama et al. (2001), em estudo sobre gravidez na adolescência, observaram que o Apgar no primeiro minuto tem maior concentração de asfixia moderada e gra- 
ve (Apgar <7) nos recém-nascidos de mães entre 15 e 19 anos, em relação aos filhos de mães de 20 a 24 anos. Quanto ao Apgar no quinto minuto, não foram encontradas significativas diferenças entre os dois grupos etários estudados.

O Apgar no quinto minuto indica estado de oxigenação do recém-nascido no período pré e intraparto, e é considerado importante preditor do bem-estar e do prognóstico inicial do recém-nascido, sinalizando para o bom estado desse a partir de valores acima de 7 (GOLDENBERG; FIGUEIREDO; SILVA, 2005).

Camiña (2005), em estudo sobre a prevalência de baixo peso ao nascer, mostrou que as mães com idade inferior a 15 anos têm maior prevalência de recémnascidos de baixo peso, com 13,3\% do total de nascimentos. Ainda, associados ao baixo peso ao nascer, foram identificados como altamente significante a idade da mãe (inferior aos 15 anos), escolaridade (menos de 4 anos de estudo), número de consultas pré-natal (menos de 6) e idade gestacional (menor que 37 semanas).

Na revisão bibliográfica feita por Chatkin (2005), o baixo peso ao nascer e a prematuridade parecem influenciar doenças de função pulmonar. O baixo peso ao nascer foi associado ao déficit da função pulmonar independentemente da idade gestacional, sugerindo que a nutrição e o ambiente intra-uterino pode ser fator determinante para o desenvolvimento e crescimento pós-natal das vias aéreas. 
Objetivos 


\subsection{Objetivo geral}

Analisar o estado nutricional, os resultados obstétricos e os parâmetros clínicos dos recém-nascidos de mães adolescentes, atendidas para resolução da gravidez na MATER - Maternidade do Complexo Aeroporto, no ano 2005.

\subsection{Objetivos específicos}

- Caracterizar as adolescentes grávidas de acordo com as variáveis sociodemográficas (idade, escolaridade e estado marital).

- Identificar a situação do cuidado pré-natal de mães adolescentes (número de consultas e estado nutricional), paridade e intercorrências do parto.

- Descrever os resultados antropométricos e as condições clínicas dos recémnascidos.

- Relacionar o estado nutricional de mães adolescentes com condições clínicas dos recém-nascidos.

- Relacionar os resultados obstétricos das adolescentes com parâmetros clínicos dos recém-nascidos. 
Metodologia 


\subsection{Desenho do estudo}

O presente trabalho foi desenvolvido com abordagem quantitativa, sendo um estudo retrospectivo, com dados secundários resultantes do levantamento dos prontuários de mães adolescentes, cuja resolução do parto ocorreu na MATER, no ano 2005.

\subsection{Local do estudo}

Os dados da pesquisa foram coletados na Maternidade do Complexo Aeroporto (MATER), localizada no Distrito Sanitário Norte da cidade de Ribeirão Preto, município do interior paulista. Trata-se de entidade médico-social filantrópica, que pertence à Fundação Sinhá Junqueira, destinada ao atendimento integral de mulheres gestantes vinculadas ao Sistema Único de Saúde (SUS). A MATER foi criada em março de 1998, em terreno cedido pela Prefeitura Municipal. Atende região com mais de 150000 habitantes, e tem a missão de prestar assistência humanizada às gestantes carentes e recém-nascidos, incentivando o parto normal, aleitamento materno e alojamento conjunto, cursos para gestantes e puérperas. É referência para doze unidades básicas de saúde e campo de estágio para os alunos de graduação e pósgraduação da Faculdade de Medicina de Ribeirão Preto (FMRP) e da Escola de Enfermagem de Ribeirão Preto (EERP) da Universidade de São Paulo.

No período de 2000 a 2005, ocorreram 16135 partos, com média mensal de 224. No ano 2005, foram 2679 partos, dos quais 656 em parturientes adolescentes, representando $24,48 \%$ dos nascimentos da Maternidade.

\section{3 População}


A população deste estudo foi constituída pelas adolescentes e seus respectivos recém-nascidos, cuja resolução do parto ocorreu na referida instituição, no período de janeiro a dezembro de 2005.

Optou-se pela definição de adolescentes da Organização Mundial da Saúde, que compreende aquelas com idade entre 10-19 anos, considerando como préadolescentes aquelas de 10 a 14 anos e adolescentes, propriamente ditas, as de 15 a 19 anos.

Considerou-se 3 critérios de exclusão para as mães e 2 para os recémnascidos. Para as mães:

- adolescentes que apresentaram doenças crônicas;

- adolescentes que tiveram gravidez gemelar;

- registro de dados incompletos no prontuário, nas variáveis peso, idade gestacional pelo ultra-som e estatura.

Como critérios de exclusão para os recém-nascidos foram considerados:

- óbito fetal;

- ausência de registro, ou registro incompleto, nas variáveis antropométricas e clínicas do recém-nascido (peso, estatura, perímetro cefálico, índice de Apgar)

Os prontuários selecionados corresponderam àqueles pertencentes às adolescentes grávidas com idade entre 10 e 19 anos, cuja resolução do parto ocorreu no ano 
2005. Foi identificado o total de 656 prontuários, dos quais 73 tinham dados incompletos, restando 583 prontuários que compuseram a população do estudo.

\subsection{Variáveis do estudo}

\subsubsection{Variáveis sociodemográficas}

- Idade, escolaridade e estado marital.

\subsubsection{Variáveis maternas: explicativas ou independentes}

- Paridade, número de consultas pré-natal.

- Relação peso/altura/idade gestacional (IG) peso da mãe, estatura da mãe, semanas por ultra-som.

- Consumo de álcool e uso de tabaco.

- Idade gestacional e sangramento pós-parto.

- Tipo de parto: vaginal (parto vaginal com bloqueio espinhal, parto vaginal com episiotomia, parto vaginal com fórceps), cesariana (indicação de cesariana), intercorrências no parto e puerpério.

\subsubsection{Variáveis do recém-nascido: resposta ou desfecho} (dependentes)

- Peso, estatura, perímetro cefálico.

- Apgar no primeiro e quinto minutos de vida.

- Procedimentos de atenção imediata: aspiração de vias aéreas superiores, uso de oxigênio, uso de máscara e ambu, entubação traqueal, aspiração gástrica e lavagem gástrica.

- Intercorrências do neonato. 


\section{Descrição das variáveis sociodemográficas}

- Idade - registrou-se a data de nascimento da mãe e de seu respectivo $\mathrm{RN}$, para se obter a idade exata das mães adolescentes em anos completos.

- Escolaridade - foram consideradas as seguintes categorias: analfabeta, ensino fundamental incompleto, ensino fundamental completo, ensino médio incompleto, ensino médio completo, universitário incompleto e universitário completo, de acordo com as Diretrizes e Bases da Educação Nacional, Lei No 9493.

- Estado civil - foram consideradas as seguintes categorias: casadas, mora junto (independentemente de sua situação legal), solteira, separada ou divorciada e viúva.

Descrição das variáveis maternas

- Paridade - foi considerado o número de gravidezes, inclusive a gravidez atual e os abortos.

- Número de controles/consultas pré-natal - foram considerados o número de controles/consultas pré-natais durante toda a gravidez, tendo sido agrupados da seguinte maneira: até 5 , de 6 a 12 e 13 ou mais controles/consultas. 
- Peso da mãe - foi considerado o peso da mãe registrado na última consulta pré-natal.

- Estatura da mãe - foi considerada a estatura materna constante da ficha de controle pré-natal.

- Semanas por ultra-som - foram coletadas as semanas de gravidez de acordo com o resultado de ultra-som registrado na última consulta pré-natal.

- Relação peso/altura/IG - para poder determinar o incremento adequado do peso, usou-se o nomograma de Rosso (Anexo A), que permite realizar o cálculo da porcentagem de peso/estatura da mulher grávida, e projeta-la na curva. O uso do nomograma consiste em calcular a porcentagem de peso para estatura da mulher, comparando com a idade gestacional. A curva de Rosso assinala áreas com categorias sobre o estado nutricional como baixo peso, peso normal, sobrepeso e obesidade. No caso especial da adolescente, recomenda-se incrementar um quilo a mais do que indica a curva (DIRECCIÓN DE SALUD MATERNO INFANTIL, 1996).

Vale ressaltar que foi utilizada a Curva de Rosso para analisar o estado nutricional, por limitações encontradas em um estudo retrospectivo. A ausência de dados nos prontuários, como o registro do peso pré-gravídico e peso inicial da gravidez, restringiram a possibilidade de utilizar-se o Índice de Massa Corporal (IMC). Da mesma forma, o instrumento proposto pelo Centro Latino-americano de Perinatologia (CLAP), adotado pelo Ministério da Saúde do Brasil, não contempla indicadores 
para avaliação acima de 39 semanas de gestação e estatura acima de 1,69 m, não se identificando na literatura a forma de calcular a progressão desses parâmetros.

- Fumante - foi coletada a resposta afirmativa ou negativa, encontrada nos prontuários, sobre o consumo de cigarros durante a gravidez.

- Álcool - foi coletada a resposta afirmativa ou negativa encontrada nos prontuários, sobre o consumo de álcool durante a gravidez.

- Idade gestacional - foi coletado a idade gestacional, segundo o resultado do último ultra-som, sendo classificada como: antes das 37 semanas/ pré-termo, de 37 semanas a 42 semanas, a termo, e como póstermo; mais de 42 semanas de gravidez.

- Sangramento - foi coletado o dado sangramento vaginal pós-parto de acordo com a quantidade mencionada, sendo pouco, médio ou grande, tanto para o parto vaginal como para o parto via alta (cesariana).

- Tipo de parto - foram considerados duas categorias, parto vaginal e parto cesariana.

- Parto vaginal com bloqueio espinhal - foi coletada a afirmação ou negação de se ter feito o procedimento de bloqueio espinhal nos partos vaginais.

- Parto vaginal com episiotomia - foi coletada a afirmação ou negação de se ter realizado o procedimento da episiotomia durante o trabalho de parto.

- Parto vaginal com fórceps - foi coletada a afirmação ou negação de se ter usado o fórceps durante o trabalho de parto. 
- Indicação de cesariana - foram coletadas as indicações médicas pela qual o parto teve resolução por cesariana.

- Intercorrências no parto e puerpério - foi considerado o registro de intercorrências maternas informadas nos prontuários analisados.

\section{Descrição das variáveis do recém nascido}

- Sexo do recém-nascido - foi coletado o sexo do RN como masculino e feminino.

- Peso de recém-nascido - verificado o peso do $\mathrm{RN}$, de acordo com as seguintes categorias: baixo peso ao nascer (menor ou igual a 2500 gramas), peso insuficiente ao nascer (de 2501 a 3000 gramas), peso adequado ao nascer (3 001 a 4000 gramas) e macrossomia (4 001 gramas ou mais).

- Estatura do recém-nascido - foi coletada a estatura do recém-nascido, classificada dentro dos parâmetros: normais, entre 48 e 52 centímetros; os outros valores estão indicados como: acima do normal e abaixo do normal.

- Perímetro cefálico - foi coletado o dado de perímetro cefálico do recém- nascido e classificado dentro dos parâmetros: normais, entre 32 e 36 centímetros; os outros valores estão categorizados como: acima do normal e abaixo do normal.

- Apgar - foi coletada a pontuação do Apgar ao $1^{\circ}$ e ao $5^{\circ}$ minuto de vida, sendo agrupada de acordo com o risco, considerando-se que a pon- 
tuação 0 a 3 representa asfixia severa, de 4 a 6 significa asfixia moderada e de 7 a 10 indicam ausência de dificuldade à adaptação de vida extra-uterina.

- Procedimentos de cuidado imediato - foram consideradas as intervenções assinaladas na ficha de recepção do recém-nascido, tais como aspiração de vias aéreas superiores, uso de oxigênio, uso de máscara e ambu, entubação traqueal, aspiração gástrica e lavagem gástrica.

- Intercorrências do recém-nascido - foram considerados os registros de intercorrências neonatais descritos nos prontuários analisados.

\subsection{Aspectos éticos}

Este estudo foi avaliado e aprovado pelo Comitê de Ética em Pesquisa da Escola de Enfermagem de Ribeirão Preto-USP, com autorização da instituição (MATER) onde o estudo foi realizado. Foi solicitada a dispensa da assinatura do termo de consentimento livre e esclarecido, tendo em vista tratar-se de estudo de análise documental (Anexo B).

\subsection{Coleta de dados}

A coleta de dados foi realizada no período de 4 de julho a 10 de outubro de 2006, a partir da análise dos prontuários das adolescentes, cuja resolução do parto ocorreu na Maternidade do Complexo Aeroporto no ano 2005. 
Foi elaborado um formulário como instrumento de coleta de dados para o registro das informações sobre as condições sociodemográficas, os resultados obstétricos e resultados clínicos dos recém-nascidos (Apêndice A).

\subsection{Análise de dados}

Após codificação e elaboração de um dicionário (codebook) para cada uma das variáveis, os dados foram alimentados e validados mediante dupla entrada (digitação) no aplicativo MS EXCEL XP. Resolvidas as inconsistências, o banco de dados foi importado no programa estatístico SPSS (Statistical Package for the Social Science), versão 15.0, utilizado na análise exploratória uni, bi e multivariável, bem como na apresentação dos resultados. De fato, as variáveis qualitativas (dicotômicas, politômicas e ordinais) foram analisadas em tabelas de freqüência e de contingência (freqüências simples e medidas de associação). Para as quantitativas, foram calculadas medidas-resumo de tendência central (média e mediana) e de dispersão ou variabilidade (desvio padrão e separatrizes).

$\mathrm{Na}$ análise da relação entre as variáveis respostas (medidas do recém-nascido) e preditoras (em geral, medidas obstétricas maternas), selecionadas e discutidas mais adiante, foram empregadas medidas de associação bivariada (coeficientes gama e $d$ de Sommer); e regressão logística múltipla por dicotomização dos desfechos escolhidos, cuja finalidade precípua foi controlar e ajustar a razão de chances (medida de 
risco) na presença de potenciais variáveis de confusão, quando a análise estratificada não se apresentava adequada. 
Resultados e discussão 


\section{Resultados e discussão}

Os resultados e a discussão dos dados referem-se à caracterização sociodemográfica das adolescentes grávidas (idade, escolaridade, estado civil), bem como os resultados obstétricos (número de consultas pré-natal, paridade, tipo de parto), os dados antropométricos das adolescentes, o estado nutricional das mesmas e as intercorrências do parto cuja resolução ocorreu na Maternidade do Complexo Aeroporto, Ribeirão Preto SP.

A distribuição dos resultados antropométricos e as condições clínicas dos recém-nascidos serão apresentadas e discutidos com base nas relações entre o estado nutricional das mães adolescentes e as condições clínicas dos recém-nascidos. 


\subsection{Perfil sociodemográfico das adolescentes}

Para caracterizar as adolescentes grávidas foram utilizadas as seguintes variáveis sociodemográficas: idade, escolaridade e estado marital, apresentadas na Tabela 1.

Tabela 1 - Distribuição quanto ao estado marital e escolaridade das adolescentes com resolução do parto na MATER. Ribeirão Preto SP, 2005

\begin{tabular}{|c|c|c|c|c|c|c|}
\hline \multirow[b]{2}{*}{ VARIÁVEL } & \multicolumn{6}{|c|}{ IDADE $(n=585)$} \\
\hline & \multicolumn{2}{|r|}{$10-14$} & \multicolumn{2}{|c|}{$15-19$} & \multicolumn{2}{|c|}{ TOTAL } \\
\hline \multicolumn{7}{|l|}{ Estado marital } \\
\hline $\begin{array}{l}\text { Casada } \\
\text { Mora junto } \\
\text { Solteira } \\
\text { Faltante }\end{array}$ & $\begin{array}{l}2 \\
9 \\
11 \\
0\end{array}$ & $\begin{array}{r}(9,1 \%) \\
(40,9 \%) \\
(50,0 \%) \\
(0 \%)\end{array}$ & $\begin{array}{l}86 \\
303 \\
164 \\
10\end{array}$ & $\begin{array}{r}(15,3 \%) \\
(53,9 \%) \\
(29,1 \%) \\
(1,7 \%)\end{array}$ & $\begin{array}{l}88 \\
312 \\
175 \\
10\end{array}$ & $\begin{array}{r}(15,0 \%) \\
(53,3 \%) \\
(30,0 \%) \\
(1,7 \%)\end{array}$ \\
\hline \multicolumn{7}{|l|}{ Escolaridade } \\
\hline $\begin{array}{l}\text { Analfabeto } \\
\text { Ensino fundamental incompleto } \\
\text { Ensino fundamental comple- } \\
\text { to } \\
\text { Ensino médio incompleto } \\
\text { Ensino médio completo } \\
\text { Faltante }\end{array}$ & $\begin{array}{l}0 \\
13 \\
7 \\
1 \\
1 \\
0\end{array}$ & $\begin{array}{r}(0 \%) \\
(59,1 \%) \\
(31,9 \%) \\
(4,5 \%) \\
(4,5 \%) \\
(0 \%)\end{array}$ & $\begin{array}{l}2 \\
166 \\
123 \\
169 \\
88 \\
15\end{array}$ & $\begin{array}{r}(0,4 \%) \\
(29,5 \%) \\
(21,8 \%) \\
(30,0 \%) \\
(15,6 \%) \\
(2,7 \%)\end{array}$ & $\begin{array}{l}2 \\
179 \\
130 \\
170 \\
89 \\
15\end{array}$ & $\begin{array}{r}(0,3 \%) \\
(30,6 \%) \\
(22,2 \%) \\
(29,1 \%) \\
(15,2 \%) \\
(2,6 \%)\end{array}$ \\
\hline TOTAL & 22 & $(3,8 \%)$ & 563 & $(96,2 \%)$ & 585 & $(100 \%)$ \\
\hline
\end{tabular}

Verificou-se que 585 mães adolescentes estavam na faixa etária entre 15 e 19 anos (idade no dia do parto), correspondendo a 96,2\% da amostra, e 22 entre as idades 10-14 anos, correspondendo a 3,8\%. 
A idade média foi de 17,39 anos $\left(s^{1}=1,4\right)$ e a mediana de 18 anos. A idade mínima foi 13 anos e 2 meses, e a idade máxima foi 19 anos e 9 meses.

Quanto ao estado marital, a maioria das adolescentes grávidas não tinha vínculo oficial com seu parceiro (53,3\% moravam junto e 30\% eram solteiras).

As adolescentes casadas foram 88 , representando $15 \%$. Observou-se a falta de registro de dados, em relação ao estado marital, em 10 prontuários (1,7\% do total).

Em relação ao grau de escolaridade, encontrou-se que 91\% dos casos das adolescentes entre 10 e 14 anos cursaram o ensino fundamental completo ou incompleto, e somente 9\% (2) iniciaram estudos no ensino médio. Entre as adolescentes de 15 a 19 anos, 51,3\% (289) freqüentaram ou concluíram o ensino fundamental (completo e incompleto) e 45,6\% (257) o ensino médio (completo e incompleto). Em 15 (2,6\%) prontuários não havia o registro de escolaridade.

Conforme referido anteriormente, em 2005, foram realizados 656 partos de adolescentes, representando $24,48 \%$ dos nascimentos na MATER.

Gama et al. (2004), em estudo realizado no município o Rio de Janeiro, mostraram que os partos de mães adolescentes representaram $25,8 \%$ do total.

Carniel et al. (2006) encontraram no município de Campinas SP, que os partos das mães adolescentes foram $17,8 \%$ do total de nascimentos, com leve tendência de aumento para as menores de 15 anos.

Em Montes Claros MG, no período de 1997 a 2001, 21,5\% dos partos foram de adolescentes, sendo que as adolescentes entre 10 e 14 anos foram $0,6 \%$, e de 15 a 19 anos 20,9\% (GOLDENBERG; FIGUEIREDO; SILVA, 2005).

1 Desvio padrão 
Essas taxas são altas, considerando que, nos países industrializados, a porcentagem de gravidez na adolescência está em torno de 4 a 5\%. Nos Estados Unidos, em 2001, a proporção de grávidas entre 10 e 19 anos foi de 4,6\% (CARNIEL et al., 2006).

Os achados de Sabroza et al. (2004), em estudo com puérperas adolescentes no Município do Rio de Janeiro, coincidiram com os deste estudo a respeito da idade média para engravidar, sendo 17,3 anos. No mesmo estudo mostraram que a maioria das adolescentes puérperas encontrava-se fora da escola antes de engravidar, e $26,9 \%$ haviam abandonado a escola por causa de gravidezes anteriores.

Em relação à escolaridade, no estudo de Carniel et al. (2006), quase a metade das adolescentes tinha menos de 8 anos de estudo. Com baixa escolaridade e sem formação profissional, as chances de inserção no mercado de trabalho ficam ainda menores, como também o sustento familiar pode ser comprometido.

No presente estudo, somente $15,6 \%$ (88) das adolescentes entre 15 e 19 anos (563) concluíram o ensino médio, evidenciando um grupo vulnerável em relação à saúde reprodutiva e condições de vida.

Haidar; Oliveira; Nascimento (2001) associaram a baixa escolaridade materna à ocorrência de recém-nascido de baixo peso; e indicaram que essa condição pode estar relacionada com o baixo padrão socioeconômico das gestantes, menor ganho de peso na gestação e início tardio do pré-natal.

Sabroza et al. (2004) evidenciaram que a maior parte das adolescentes não tinha trabalho remunerado, dependendo financeiramente da família, ou companheiro, sendo que quase a metade $(45,9 \%)$ dos pais das crianças também eram adolescentes. As puérperas adolescentes que pertencem ao grupo das mais jovens e que não possu- 
em união consensual são aquelas que tendem a ter as piores condições sociais. $\mathrm{O}$ fato de estabelecer uniões com homens desempregados deixa a situação ainda mais precária, estando mais expostas ao risco social.

Magalhães et al. (2006) concluíram que tanto as mães adolescentes precoces como tardias, submetidas às mesmas condições socioeconômicas e à mesma assistência ao pré-natal, apresentam resultados semelhantes em relação à evolução da gestação, sendo ambas as características biológicas aceitáveis para o desempenho obstétrico satisfatório.

\subsection{Resultados obstétricos}

Foram considerados como resultados obstétricos das mães adolescentes as seguintes variáveis maternas: o número de consultas/controles pré-natal, paridade, estado nutricional, tipo de parto e intercorrências, apresentadas e discutidas a seguir.

Tabela 2 - Distribuição das mães adolescentes quanto ao controle pré-natal e paridade, MATER. Ribeirão Preto SP, 2005
VARIÁVEL
$10-14$
15- 19
TOTAL

\section{Controle pré-natal}

Até 5 controles

Entre 6 e 12 controles

13 ou mais controles

Faltante

$\begin{array}{lrlrlr}5 & (22,7 \%) & 115 & (20,4 \%) & 120 & (20,5 \%) \\ 17 & (77,3 \%) & 429 & (76,3 \%) & 446 & (76,2 \%) \\ 0 & (0 \%) & 16 & (2,8 \%) & 16 & (2,8 \%) \\ 0 & (0 \%) & 3 & (0,5 \%) & 3 & (0,5 \%)\end{array}$

\section{Paridade}

Uma gravidez

Duas gravidezes

Três gravidezes

Quatro gravidezes

Cinco gravidezes
22

0

0

0

0
$(100 \%) \quad 425$

$(0 \%) \quad 113$

$(0 \%) \quad 21$

(0\%) 1

(0\%) 3
$(75,5 \%) \quad 447$

(20,1\%) $\quad 113$

$(3,7 \%) \quad 21$

$(0,2 \%) \quad 1$

$(0,5 \%) \quad 3$
$(76,4 \%)$

$(19,3 \%)$

$(3,6 \%)$

$(0,2 \%)$

$(0,5 \%)$ 
Em relação ao controle pré-natal, 76,2\% (446) das adolescentes tiveram entre 6 e 12 consultas durante a gravidez, sendo considerado um número adequado para o cuidado pré-natal de qualidade sendo que 20,5\% (120) adolescentes tiveram menos de 6 consultas, e 2,8\% (16) mais de 13. A média foi de 7,7 consultas pré-natais, com desvio padrão de 2,6 e mediana de 8 controles.

Por consulta pré-natal entende-se a série de entrevistas ou visitas programadas da grávida com integrantes da equipe da saúde, com o objetivo de acompanhar a evolução da gravidez e obter adequada preparação para o parto, tendo que ser precoce, periódico, completo e de ampla cobertura (SCHWARCZ, et al. 2001).

O estudo de Gama et al. (2004), realizado no município do Rio de Janeiro, mostrou que quase $95 \%$ das adolescentes realizaram consulta pré-natal pelo menos uma vez e que só $42 \%$ delas compareceram a seis ou mais consultas. Os autores associaram a baixa condição de vida com ausência de controles pré-natal; também, de maneira relevante, o apoio familiar e a presença o pai da criança estão associados à adesão ao cuidado pré-natal. O fato de viver com o pai da criança, perceber a satisfação com a gravidez e sentir-se apoiada influenciaram no número de consultas realizadas pelas gestantes, assim como as atividades de educação e preparação para o cuidado infantil, levando à maior participação.

Ainda em relação à freqüência de controle pré-natal, menos de $40 \%$ das adolescentes de Montes Claros, MG tiveram mais de 6 consultas, sendo significativamente menor entre as adolescentes entre 10 e 14 anos (GOLDENBERG; FIGUEIREDO; SILVA, 2005). 
Em relação ao número de gravidezes, encontrou-se que todas as adolescentes entre 10 e 14 anos estavam na sua primeira gravidez.

Nas adolescentes de 15 a 19 anos observou-se que 75,5\% (425) engravidaram pela primeira vez e 19,3\% (113) engravidaram pela segunda vez. Encontrou-se, ainda, entre as adolescentes dessa faixa etária três, quatro e até cinco gravidezes, somando $4,4 \%(25)$. A média foi de 1,28 gravidezes por adolescente $(s=0.5)$ e a mediana de 1 gravidez por adolescente.

A repetição gestacional entre adolescentes é uma realidade em nosso meio. Estudos evidenciam que multíparas adolescentes apresentam pior nível de escolaridade, pior assistência no pré-natal, pior ganho ponderal, ausência de companheiro e menor intervalo interpartal. As multíparas adolescentes apresentam duas vezes mais riscos para o recém-nascido (PINTO e SILVA; CHINAGLIA, 2000).

A Pesquisa Nacional de Demografia e Saúde, realizada em 1996, identificou que $14 \%$ das mulheres de 15 a 19 anos de idade tinham iniciado a vida reprodutiva, seja porque já eram mães, seja porque estavam grávidas do primeiro filho, tornando evidente a vulnerabilidade das adolescentes aos agravos em saúde sexual e reprodutiva (BRASIL, 2004).

Tabagismo e consumo de álcool

Em relação ao consumo de cigarros durante a gravidez, 496 negaram seu uso, representando $84,8 \%$ do total. No entanto, boa porcentagem de adolescentes referiu ser fumante durante a gravidez (81), correspondendo a $13,8 \%$ do total. Não se identifico registro de tabagismo em $8(1,4 \%)$ prontuários. 
O consumo de álcool, durante a gravidez, foi negado em 568 dos prontuários revisados, correspondendo a $97,1 \%$ do total. Encontrou-se 10 prontuários afirmando o uso de álcool durante a gravidez, representando 1,7\%. Não havia registro em 7 prontuários $(1,2 \%)$.

Está definitivamente estabelecida a relação entre o hábito de fumar e a ocorrência de partos de crianças pequenas para idade gestacional e baixo peso ao nascer. Esse risco persiste mesmo quando se controlam variáveis como: idade, paridade e peso materno, uso de álcool e cafeína. Nos Estados Unidos, onde 30\% das mulheres fumam, estima-se que de 13 a $20 \%$ de todos os nascimentos pré-termo são devidos ao hábito de fumar (PINTO e SILVA; CHINGLIA, 2000).

Freire et al. (2005) relatam associação altamente significativa entre o consumo de bebidas alcoólicas e mulheres grávidas solteiras. Os autores apontam que a ocorrência de consumo de álcool entre as grávidas solteiras é duas vezes maior que entre as grávidas casadas, possivelmente porque a gestação nas mulheres solteiras com freqüência está associada à baixa escolaridade, baixo nível socioeconômico e gravidez não desejada.

Tabela 3 - Relação entre o peso, altura e idade gestacional de adolescentes de acordo com a curva de Rosso, MATER. Ribeirão Preto SP, 2005

\begin{tabular}{|c|c|c|c|c|c|c|}
\hline \multirow{3}{*}{$\begin{array}{l}\text { Relação peso/altura da mu- } \\
\text { lher grávida } \\
\text { Baixo peso }\end{array}$} & \multicolumn{6}{|c|}{ Idade em anos completos } \\
\hline & \multicolumn{2}{|r|}{$10-14$} & \multicolumn{2}{|c|}{$15-19$} & \multicolumn{2}{|c|}{ TOTAL } \\
\hline & 13 & $(59,1 \%)$ & 256 & $(45,5 \%)$ & 269 & $(46,0 \%)$ \\
\hline Normal & 6 & $(27,3 \%)$ & 178 & $(31,6 \%)$ & 184 & $(31,4 \%)$ \\
\hline Sobrepeso & 3 & $(13,6 \%)$ & 63 & $(11,2 \%)$ & 66 & $(11,3 \%)$ \\
\hline Obesidade & 0 & $(0 \%)$ & 66 & $(11,7 \%)$ & 66 & $(11,3 \%)$ \\
\hline
\end{tabular}


A relação peso/altura por idade gestacional mostrou alta incidência de baixo peso, sendo que 59,1\% (13) das adolescentes entre 10 e 14 anos e 45,5\% (256) adolescentes entre 15 e 19 anos tiveram baixo peso ao final da gravidez. Somando as duas faixas etárias, há 46\% (269) de adolescentes com baixo peso no final da gravidez.

As freqüências de adolescentes com sobrepeso (66 casos-11,3\%), sendo o maior percentual entre 10 a 14 anos e obesidade (66 casos-11,3\%), todas elas na faixa etária entre 15 e 19 anos, somaram $22,6 \%$ do total.

Ressalta-se que somente $31,4 \%$ das adolescentes finalizaram a gravidez com o peso normal para a idade gestacional.

O estado nutricional da mulher, antes e durante a gestação, é crítico para a saúde e sobrevivência dela e do bebê. Peso pré-gestacional inadequado acompanhado por ganho de peso insuficiente, aumenta o risco de baixo peso ao nascer, mortalidade perinatal, neonatal e infantil (RIBEIRO et al., 2002).

O ganho de peso insuficiente durante a gravidez pode trazer conseqüências prejudiciais para sua evolução. Além das condições de má nutrição materna, muitas vezes presente entre mães de baixa renda, acrescentam-se a observação de hábitos dietéticos inadequados e diminuição do apetite, provocado por estados de ansiedade, típicos entre adolescentes (PINTO e SILVA, CHINAGLIA, 2000).

Furlan et al., (2003), em estudo no ambulatório de pré-natal da Universidade Federal de São Paulo (UNIFESP-EPM) mostraram, segundo o índice de massa cor- 
poral (IMC), que 27,7\% das adolescentes iniciaram a gravidez desnutridas, $65,3 \%$ com peso normal, $4 \%$ sobrepeso e $3 \%$ com obesidade.

Os resultados do presente estudo ressaltam a necessidade de reforçar ações de cuidado pré-natal relacionadas às orientações nutricionais, bem como estimular os profissionais de saúde para a importância da avaliação e tomada de decisão no acompanhamento dos casos, em especial de gestantes adolescentes.

Tabela 4 - Distribuição segundo o tipo de parto, idade gestacional, intercorrências maternas no parto e sangramento pós-parto de adolescentes, MATER. Ribeirão Preto, SP, 2005

\begin{tabular}{|c|c|c|c|c|c|c|}
\hline \multirow[b]{2}{*}{ Tipo de parto } & \multicolumn{2}{|c|}{$10-14$} & \multicolumn{2}{|c|}{$15-19$} & \multicolumn{2}{|c|}{ TOTAL } \\
\hline & & & & & & \\
\hline Vaginal & 18 & $(81,8 \%)$ & 443 & $(78,7 \%)$ & 461 & $(78,8 \%)$ \\
\hline Cesariana & 4 & $(18,2 \%)$ & 120 & $(21,3 \%)$ & 124 & $(21,2 \%)$ \\
\hline \multicolumn{7}{|l|}{ Idade gestacional (US) } \\
\hline Pré-termo & 1 & $(4,5 \%)$ & 25 & $(4,4 \%)$ & 26 & $(4,4 \%)$ \\
\hline Termo & 21 & $(95,5 \%)$ & 526 & $(93,5 \%)$ & 547 & $(93,5 \%)$ \\
\hline Pós-termo & 0 & $(0 \%)$ & 12 & $(2,1 \%)$ & 12 & $(2,1 \%)$ \\
\hline \multicolumn{7}{|c|}{ Intercorrências maternas } \\
\hline Sim & 2 & $(9,1 \%)$ & 19 & $(3,4 \%)$ & 21 & $(3,6 \%)$ \\
\hline Não & 20 & $(90,9 \%)$ & 544 & $(96,6 \%)$ & 564 & $(96,4 \%)$ \\
\hline \multicolumn{7}{|l|}{ Sangramento pós-parto } \\
\hline Pouco & 13 & $(59,1 \%)$ & 371 & $(65,9 \%)$ & 384 & $(65,6 \%)$ \\
\hline Médio & 3 & $(13,6 \%)$ & 103 & $(18,3 \%)$ & 106 & $(18,1 \%)$ \\
\hline Grande & 0 & $(0 \%)$ & 8 & $(1,4 \%)$ & 8 & $(1,4 \%)$ \\
\hline Faltante & 6 & $(27,3 \%)$ & 81 & $(14,4 \%)$ & 87 & $(14,9 \%)$ \\
\hline TOTAL & 22 & $(3,8 \%)$ & 563 & $(96,2 \%)$ & 585 & $(100 \%)$ \\
\hline
\end{tabular}


Em relação ao tipo de parto, nota-se o predomínio do parto vaginal entre as adolescentes das duas faixas etárias, correspondendo a 78,8\% (461) adolescentes. No caso especial das adolescentes, entre 10 e 14 anos, para a maioria delas $(81,8 \%)$ a resolução do parto foi vaginal. Os partos cesarianas foram realizados em 21,2\% (124) do total de adolescentes.

Oliveira; Miquilini (2005) identificaram que, no Hospital Universitário de São Paulo (HU-USP), dos 255 partos realizados no mês de outubro de 2000, 47,8\% foram partos normais, 36,9\% cesarianas e 15,3\% fórceps (independentemente da idade materna). Em pesquisa de Furlan et al. (2003), os partos vaginais ocorreram em $80,3 \%$ das adolescentes, sendo $19,7 \%$ por via alta.

Ribeiro et al. (2000) em pesquisa comparativa dos partos em adolescentes no ano de 1978 e 1994, evidenciaram uma diminuição de parto cesariano entre as adolescentes. Segundo os autores, não houve aumento entre o baixo peso ao nascer ou prematuridade, indicando que talvez a prática médica no sentido de realizarem mais partos vaginais (incluindo o uso de fórceps), nessa faixa etária, seja um dos fatores que explique os poucos casos de baixo peso e prematuridade entre as adolescentes de seu estudo.

Os resultados de idade gestacional mostraram que 93,5\% das adolescentes tiveram gravidez a termo, sendo que a maior percentagem foi nas adolescentes entre 10 e 14 anos. A gravidez pré-termo foi observada em $26(4,4 \%)$ casos, a gravidez pós-termo em 12 (todas elas pertencem à faixa etária entre 15 e 19 anos), com porcentagem de $2,1 \%$.

A prematuridade tem sido relacionada com à idade materna, principalmente para mulheres nos extremos da vida reprodutiva. Também é relacionada ao nível 
socioeconômico, porque se correlaciona com o nível educacional, atividade e tipo de trabalho, qualidade de alimentação, acesso a serviços de saúde e oportunidades sociais (PINTO e SILVA, 2000).

Encontrou-se, no presente estudo, poucas intercorrências maternas durante o parto, com 3,6\% (21) das mães adolescentes com a necessidade de algum tipo de cuidado especial; mais freqüentemente nas adolescentes entre 10 e 14 anos,sendo que 96,4\% (564) das adolescentes tiveram parto (vaginal ou cesarianos) sem intercorrências.

Em relação ao sangramento pós-parto, 65,6\% (384) das adolescentes apresentaram pouco sangrando; em 106 adolescentes $(18,1 \%)$ o sangramento foi em média quantidade, e $8(1,4 \%)$ sangramento foi em grande quantidade; todas elas na faixa etária dos 15 a 19 anos. A ocorrência de sangramento pós-parto foi observada no impresso/registro de sala de parto, inferindo-se que o sangramento ocorreu no período do pós-parto imediato.

Sugere-se que as adolescentes jovens têm os ossos pélvicos e o canal do parto ainda em processo de crescimento, aumentando assim a indicação de cesárea, por problemas como parto obstruído ou imaturidade biológica, mas a freqüência de cesáreas com adolescentes tem sido menor que em mulheres adultas (MAGALHÃES et al., 2006).

A prevenção de nascimentos pré-termo tem sido focalizada principalmente pela crescente incidência em todo o mundo, assim como suas complicações nos diferentes aspectos do desenvolvimento. Estudo com extensa casuística brasileira aponta para problemas sociais, como mães primíparas, ausência do companheiro e o hábito de fumar entre os principais fatores de risco (FUNAYAMA, 2005). 
Tabela 5 - Distribuição de indicações de cesárea em adolescentes, MATER. Ribeirão Preto SP, 2005

\begin{tabular}{|l|c|}
\hline \hline \multirow{2}{*}{ VARIÁVEL } & Mães adolescentes $(\mathrm{n}=585)$ \\
\cline { 2 - 2 } & $\mathbf{( n )} \quad \mathbf{( \% )}$ \\
\hline
\end{tabular}

\section{Indicação de cesariana}

Sofrimento fetal agudo

Parada secundária da dilatação

Desproporção cefalopélvica

Falha na indução

Apresentação pélvica

Cesariana prévia recente

Sofrimento fetal crônico

Interatividade (mais de 3 cesáreas)

Iminência de ruptura uterina

Hipertensão arterial

Macrossomia fetal

Prolapso do cordão

Bolsa rota por mais de 24 horas

Taquisistolia

Apresentação anômala
6,3

5,3

3,1

2,4

1,2

0,5

0,5

0,3

0,3

0,3

0,2

0,2

0,2

0,2

0,2 
O estudo identificou que $21,2 \%$ (124) das adolescentes grávidas finalizaram o parto por via alta (cesárea), sendo a indicação médica mais freqüente o sofrimento fetal agudo, com 6,3\% (37) dos casos; 5,3\% (31) por parada secundária da dilatação e 3,1\% (18) por desproporção cefalopélvica.

As outras indicações foram em menor proporção: a falha na indução do parto $(2,4 \%)$, apresentação pélvica $(1,2 \%)$, cesariana prévia recente $(0,5 \%)$, sofrimento fetal crônico $(0,5 \%)$, mais de 3 cesarianas $(0,3 \%)$, iminência de ruptura uterina $(0,3 \%)$, hipertensão arterial $(0,3 \%)$, macrossomia fetal $(0,2 \%)$, prolapso do cordão $(0,2 \%)$ e bolsa rota por mais de 24 horas $(0,2 \%)$

A cesariana é um grande avanço da medicina, transformando-se numa alternativa segura ao parto vaginal; no entanto, desde a década de 90, as indicações para sua realização vêm crescendo indiscriminadamente, sendo utilizada de forma abusiva, voltando-se contra os objetivos para os quais foram idealizadas, assim aumentando riscos de morbidade materna e perinatal (DIAS; DESLANDES, 2004).

Tabela 6 - Distribuição das intercorrências maternas no parto e puerpério de adolescentes, MATER. Ribeirão Preto SP, 2005

\begin{tabular}{|c|c|c|}
\hline \multirow[b]{2}{*}{ VARIÁVEL } & \multicolumn{2}{|c|}{ Mães adolescentes $(n=585)$} \\
\hline & (n) & $(\%)$ \\
\hline \multicolumn{3}{|c|}{$\begin{array}{l}\text { Intercorrências maternas no parto } \\
\text { e no puerpério }\end{array}$} \\
\hline Ausente & 564 & 96,4 \\
\hline Infecção puerperal & 5 & 0,9 \\
\hline Mastite & 5 & 0,9 \\
\hline Hipotonia uterina & 3 & 0,5 \\
\hline Retenção placentária & 2 & 0,5 \\
\hline
\end{tabular}




\begin{tabular}{lcc} 
Laceração de terceiro grau & 2 & 0,3 \\
Infecção urinaria & 2 & 0,3 \\
Deiscência de episiorrafia & 1 & 0,2 \\
\hline TOTAL & 585 & 100,0 \\
\hline \hline
\end{tabular}

As mães adolescentes que apresentaram alguma intercorrência durante o parto ou puerpério foram 3,6\% (21). Dentre as intercorrências no parto, encontrou-se: retenção placentária, com $0,5 \%$ e laceração de terceiro grau $0,2 \%$. As intercorrências durante o puerpério foram de 3,6\% do total de partos das adolescentes grávidas, entre as quais: infecção puerperal $(0,9 \%)$, mastite $(0,9 \%)$, hipotonia uterina $(0,5 \%)$, infecção urinária $(0,3 \%)$ e deiscência de episiorrafia $(0,2 \%)$.

Tabela 7 - Distribuição das adolescentes quanto aos procedimentos durante o trabalho de parto vaginal, MATER. Ribeirão Preto SP, 2005

\section{VARIAVEIS}

10-14

15-19

TOTAL

\section{Bloqueio espinhal}

Não se aplica (cesárea)

Sim

$4 \quad(18,2 \%) \quad 120$

$(21,3 \%) \quad 124$

$(21,2 \%)$

Não

$15 \quad(68,2 \%) \quad 340$

$(60,4 \%) \quad 355$

$(60,7 \%)$

$3 \quad(13,6 \%) \quad 103$

$(18,3 \%) \quad 106$

$(18,1 \%)$

\section{Uso de fórceps}

Não se aplica (cesárea)

Sim

$\begin{array}{lrlrlr}4 & (18,2 \%) & 120 & (21,3 \%) & 124 & (21,2 \%) \\ 0 & (0 \%) & 24 & (4,3 \%) & 24 & (4,1 \%) \\ 18 & (81,8 \%) & 419 & (74,4 \%) & 437 & (74,7 \%)\end{array}$

Não

Episiotomia
Não se aplica (cesárea)
Sim
Não
Faltante

4
10
8
0

\section{$(18,2 \%) \quad 120$}

$(45,4 \%)$

$(36,4 \%)$

(0\%)
(21,3\%) 124

$(34,6 \%) \quad 205$

$(42,7 \%) \quad 248$

$(1,4 \%) \quad 8$
$(21,2 \%)$

$(35,0 \%)$

$(42,4 \%)$

$(1,4 \%)$ 
Em relação aos procedimentos efetuados no parto vaginal, o bloqueio espinhal, para aliviar a dor do parto, foi realizado em 60,7\% (355) adolescentes. Somente $18,1 \%$ (106) das adolescentes que tiveram partos normais não foram submetidas ao bloqueio espinhal, dentre as quais se incluem aquelas que foram admitidas em trabalho de parto expulsivo.

Encontrou-se que $24(4,1 \%)$ adolescentes entre as idades de 15 a 19 anos necessitaram da ajuda do fórceps durante o parto. Nota-se que, entre as adolescentes entre 10 e 14 anos, não foi observado o uso de fórceps. No total de 74,7\% (437) adolescentes não foram utilizados o fórceps.

O procedimento da episiotomia foi feito em 35\% (205) das adolescentes, sendo que 42,4\% (248) não precisaram desse procedimento. Esse dado não foi registrado em $8(1,4 \%)$ prontuários.

Ressalta-se que em 21,2\% (124) das adolescentes esses procedimentos não foram aplicáveis por tratar-se de mulheres submetidas à cesárea.

O bloqueio espinhal é um método de alívio da dor que exige condições materiais e técnicas, somente podendo ser aplicados em hospitais bem equipados e com funcionários suficientes. Em muitos países, essas condições técnicas não estão geralmente disponíveis, especialmente no parto normal. Entretanto, a demanda por esse método é em parte determinada culturalmente, e a qualidade da assistência ao parto não depende da disponibilidade dessas condições, elas não fazem parte dos cuidados essenciais ao parto. No entanto, os métodos farmacológicos nunca devem substituir a atenção pessoal e o carinho (OMS, 1996).

Existem controvérsias sobre as técnicas de analgesias durante o parto, porque podem interferir no trabalho de parto e na vitalidade do recém-nascido. Eberle et al. 
(2006) concluíram que a técnica de analgesia peridural contínua, sempre em pequenas doses, não influenciou nos resultados do parto e no índice de Apgar.

Segundo a OMS (1996), existem poucas dúvidas sobre a utilidade da analgesia peridural no trabalho de parto complicado. Entretanto, se ela for administrada em uma gestante de baixo risco, há dúvidas se o procedimento resultante ainda pode ser chamado parto normal. A analgesia peridural é um dos exemplos mais marcantes da medicalização do parto normal, transformando um evento fisiológico num procedimento médico.

A utilização do fórceps torna-se justificável em casos que ameacem o bemestar materno, ou fetal, e que possam ser revertidos ou melhorados pelo uso adequado e seguro do instrumento. O uso correto do fórceps tem comprovada eficácia em evitar a hipóxia fetal, abreviando o período expulsivo e minimizando os riscos de seqüelas neurológicas (BRASIL, 2001).

A episiotomia é realizada com freqüência, mas sua incidência é variável. Nos Estados Unidos, são realizadas em torno de 50 a 90\% em primíparas. Oliveira e Miquilini (2005) referem que a episiotomia está indicada para todas as primíparas e para as multíparas com episiotomia anterior, portanto, o procedimento acaba sendo praticado em quase todos os partos como rotina, sem analisar outros fatores, as vantagens ou desvantagens para cada paciente.

No estudo exploratório feito no Hospital Universitário da Universidade de São Paulo (HU-USP), a episiotomia ocorreu em 76,2\% dos partos normais, sendo o tipo de episiotomia mais citada a média lateral direita (92\%). Nesse estudo, as justificativas para realizar a episiotomia foram: procedimento para aprendizado durante a 
formação acadêmica, por ser de rotina, ter menor risco de lesão do esfíncter anal e menor risco de complicações.

Não existem evidências confiáveis de que o uso rotineiro e generalizado da episiotomia tenha um efeito benéfico, mas há evidências claras de que podem causar dano, sendo recomendado o uso limitado dessa intervenção. Segundo a OMS, a porcentagem de episiotomias (10\%) alcançada no estudo inglês, sem dano para a mãe ou para o recém-nascido, seria uma boa meta a adotar (OMS, 1996).

Os índices encontrados nesta pesquisa ainda estão muito acima da meta proposta pela OMS. No entanto, vale ressaltar que a Instituição em estudo tem se empenhado em reduzir os índices de intervenções rotineiras, visando ampliar as ações de humanização do parto, dentre eles a episiotomia.

\subsection{Caracterização dos recém-nascidos}

Para a caracterização dos recém-nascidos foram identificados e trabalhados os resultados antropométricos e as condições clínicas apresentadas e discutidas a seguir.

Tabela 8 - Distribuição das características antropométricas e clínicas dos recémnascidos de mães adolescentes, MATER. Ribeirão Preto SP, 2005

\begin{tabular}{|c|c|c|c|c|c|c|}
\hline VARIÁVEL & \multicolumn{2}{|c|}{ Masculino } & \multicolumn{2}{|c|}{ Feminino } & \multicolumn{2}{|c|}{ TOTAL } \\
\hline \multicolumn{7}{|l|}{ Peso } \\
\hline Baixo peso ao nascer & 11 & $(3,8 \%)$ & 12 & $(4,1 \%)$ & 23 & $(3,9 \%)$ \\
\hline Peso insuficiente ao nascer & 74 & $(25,2 \%)$ & 93 & $(31,8 \%)$ & 167 & $(28,5 \%)$ \\
\hline Peso adequado ao nascer & 198 & $(67,6 \%)$ & 181 & $(62,0 \%)$ & 379 & $(64,9 \%)$ \\
\hline Macrossomia & 10 & $(3,4 \%)$ & 6 & $(2,1 \%)$ & 16 & $(2,7 \%)$ \\
\hline \multicolumn{7}{|l|}{ Estatura } \\
\hline \multicolumn{7}{|l|}{ Abaixo do normal } \\
\hline Normal & 43 & $(14,7 \%)$ & 62 & $(21,2 \%)$ & 105 & $(17,9 \%)$ \\
\hline \multirow[t]{2}{*}{ Acima do normal } & 229 & $(78,2 \%)$ & 227 & $(77,7 \%)$ & 456 & $(77,9 \%)$ \\
\hline & 21 & $(7,2 \%)$ & 3 & $(1,0 \%)$ & 24 & $(4,1 \%)$ \\
\hline
\end{tabular}




\begin{tabular}{|c|c|c|c|c|c|c|}
\hline $\begin{array}{l}\text { Abaixo do normal } \\
\text { Normal } \\
\text { Acima do normal }\end{array}$ & $\begin{array}{l}18 \\
248 \\
27\end{array}$ & $\begin{array}{r}(6,1 \%) \\
(84,7 \%) \\
(9,2 \%)\end{array}$ & $\begin{array}{l}23 \\
254 \\
15\end{array}$ & $\begin{array}{r}(7,9 \%) \\
(87,0 \%) \\
(5,1 \%)\end{array}$ & $\begin{array}{l}41 \\
502 \\
42\end{array}$ & $\begin{array}{r}(7,0 \%) \\
(85,8 \%) \\
(7,2 \%)\end{array}$ \\
\hline \multicolumn{7}{|c|}{ Apgar ao minuto de vida } \\
\hline $\begin{array}{l}\text { Asfixia severa } \\
\text { Asfixia moderada } \\
\text { Sem asfixia }\end{array}$ & $\begin{array}{l}14 \\
29 \\
250\end{array}$ & $\begin{array}{r}(4,8 \%) \\
(9,9 \%) \\
(85,3 \%)\end{array}$ & $\begin{array}{l}15 \\
23 \\
254\end{array}$ & $\begin{array}{r}(5,1 \%) \\
(7,9 \%) \\
(87,0 \%)\end{array}$ & $\begin{array}{l}29 \\
52 \\
504\end{array}$ & $\begin{array}{r}(5,0 \%) \\
(8,9 \%) \\
(86,1 \%)\end{array}$ \\
\hline \multicolumn{7}{|c|}{$\begin{array}{l}\text { Apgar ao quinto minuto de } \\
\text { vida }\end{array}$} \\
\hline $\begin{array}{l}\text { Asfixia moderada } \\
\text { Sem asfixia }\end{array}$ & $\begin{array}{l}4 \\
289\end{array}$ & $\begin{array}{r}(1,4 \%) \\
(98,6 \%)\end{array}$ & $\begin{array}{l}4 \\
288\end{array}$ & $\begin{array}{r}(1,4 \%) \\
(98,6 \%)\end{array}$ & $\begin{array}{l}8 \\
577\end{array}$ & $\begin{array}{r}(1,4 \%) \\
(98,6 \%)\end{array}$ \\
\hline TOTAL & 293 & $(50,1 \%)$ & 292 & $(49,9 \%)$ & 585 & $(100 \%)$ \\
\hline
\end{tabular}

Em relação ao peso do recém-nascido, encontrou-se o total de 3,9\% (23) RNs com baixo peso ao nascer. Peso insuficiente foi predominantemente no sexo feminino $(93$ casos) e 74 do sexo masculino, somando 167 (28,5\%). Os recém-nascidos com peso adequado foram $64,9 \%$ (379), dos quais a maioria eram meninos (198) sendo 181 meninas. Também se observou a presença de 16 (2,7\%) recém-nascidos macrossômicos.

O peso médio para os recém-nascidos de sexo masculino foi de $3223 \mathrm{~g}$ ( $\mathrm{s}$ =416g), uma mediana de 3205g. O peso máximo encontrado foi de $4405 \mathrm{~g}$ e o mínimo de $1785 \mathrm{~g}$. Para o sexo feminino, encontrou-se a média de $3134 \mathrm{~g}(s=390)$, e mediana de $3140 \mathrm{~g}$. O peso máximo encontrado foi de $4130 \mathrm{~g}$ e o mínimo de $1925 \mathrm{~g}$.

Observou-se que a estatura de $77,9 \%$ dos recém nascidos foi normal. Como estaturas abaixo do normal, encontrou-se 62 casos em RN do sexo feminino e 43 do sexo masculino, totalizando 105 casos $(17,9 \%)$. Com estatura acima do normal, encontrou-se $21(7,2 \%)$ casos do sexo masculino, do total de $24(4,1 \%)$ crianças do estudo. 
A média de estatura para os recém-nascidos de sexo masculino foi 49,2cm ( $s$ $=2,2$ ) e a mediana de $49,5 \mathrm{~cm}$. Encontrou-se a estatura máxima de $55 \mathrm{~cm}$ e mínima de $34 \mathrm{~cm}$. Para o sexo feminino, a média foi de $48,7 \mathrm{~cm}(\mathrm{~s}=1,8)$, uma mediana de $49 \mathrm{~cm}$, com estatura máxima de 53,5cm e mínima de $43,5 \mathrm{~cm}$.

Em relação ao perímetro cefálico, a maioria dos recém nascidos (502) encontrava-se dentro do normal $(85,8 \%)$; o perímetro cefálico acima do normal foi mais freqüente no sexo masculino, com 27 casos, sendo 15 no sexo feminino, somando 42 casos $(7,2 \%)$. Com perímetro cefálico abaixo do normal habia 23 meninas e 18 meninos, totalizando 41 casos $(7 \%)$.

A média para o perímetro cefálico dos recém-nascidos do sexo masculino foi de $34,3 \mathrm{~cm}(s=1,5)$, a mediana de $34,5 \mathrm{~cm}$, com perímetro máximo de $40 \mathrm{~cm}$ e mínimo de $30 \mathrm{~cm}$. Para o perímetro cefálico dos recém-nascidos do sexo feminino, a média foi de $33,7 \mathrm{~cm}(\mathrm{~s}=1,5)$, a mediana de 34 , o perímetro máximo $38 \mathrm{~cm}$, e o mínimo $29 \mathrm{~cm}$.

Em relação ao índice de Apgar do primeiro minuto de vida, a asfixia severa esteve presente em 5\% dos recém-nascidos; $8,9 \%$ tiveram asfixia moderada, dos quais 29 eram meninos e 23 meninas. O índice de Apgar normal foi obtido na maioria dos recém-nascidos, com $86,1 \%$.

Para os recém-nascidos de sexo masculino a média desse índice foi de 8,16 $(s=2)$, a mediana foi 9 , com pontuação máxima de 10 e com mínima de 1 . Para as recém-nascidas, a média foi de $8,3(s=1,9)$, a mediana de 9 , a pontuação máxima de 10 e a mínima de 1.

Observou-se, no índice de Apgar no quinto minuto, que quase todos os recém- nascidos (577) conseguiram pontuação dentro dos padrões normais $(98,6 \%)$ do 
total; 8 recém-nascidos apresentaram asfixia moderada, divididos igualmente entre ambos os sexos.

A média do índice de Apgar ao quinto minuto de vida para os recém-nascidos do sexo masculino foi de 9,6 $(s=0,7)$, mediana de 10 , pontuação máxima de 10 e mínima de 4. A média do índice de Apgar ao quinto minuto de vida dos recémnascidos do sexo feminino foi de $9,7(s=0,7)$ mediana de 10 , como pontuação máxima de 10 e mínima 5.

O peso do recém-nascido depende do sexo e da etnia, sendo que os meninos são mais pesados que as meninas; além da relação direta com a idade gestacional, com as condições do pré-natal, doenças e nutrição maternas entre outros fatores (BARROS, 2000).

Carniel et al. (2006), no estudo com filhos de adolescentes em Campinas SP, mostraram que o baixo peso ao nascer foi de $9,7 \%$ e o percentual de crianças com peso insuficiente para idade gestacional foi de $24,8 \%$.

Em relação ao perímetro cefálico, o pré-termo, depois de um atraso inicial, aumenta a velocidade de crescimento, aproximando-se e ultrapassando o esperado para o crescimento fetal; em seguida, a curva atinge os padrões normais. Entretanto, nas crianças com retardo de crescimento intra-uterino, as curvas de perímetro cefálico se mantêm abaixo do esperado para a idade (MACCHIAVERNI, BARROS FILHO, 1998).

A asfixia ao nascimento encontra-se entre as principais causas de óbito neonatal em todos os países. Segundo a OPAS (Organização Pan-americana de Saúde), no final do século $\mathrm{XX}$, as causas perinatais foram responsáveis por $38 \%$ das mortes 
abaixo de 5 anos nas Américas, sendo 41\% decorrente de problemas na gestação e parto, dos quais a asfixia perinatal responde por 21\% (FUNAYAMA, 2005).

Tabela 9 - Distribuição dos procedimentos de atenção imediata aos recém-nascidos de mães adolescentes, MATER. Ribeirão Preto SP, 2005

\begin{tabular}{|l|c|c|c|}
\hline \hline & \multicolumn{3}{|c|}{ Sexo $(\mathbf{n}=585)$} \\
\hline VARIÁVEL & Masculino & Feminino & TOTAL \\
\hline
\end{tabular}

$\begin{array}{lrrrrrr}\begin{array}{l}\text { AVAS } \\ \text { (aspiração de vias aéreas superiores) }\end{array} & 222 & (75,8 \%) & 224 & (76,7 \%) & 446 & (76,2 \%) \\ \text { Sim } & 71 & (24,2 \%) & 68 & (23,3 \%) & 139 & (23,8 \%) \\ \text { Não } & & & & & & \end{array}$

\section{Uso de oxigênio}

Sim

$104 \quad(35,5 \%) \quad 93$

$(31,8 \%) \quad 197$

$(33,7 \%)$

Não

$189 \quad(64,5 \%) \quad 199$

$(68,2 \%) \quad 388 \quad(66,3 \%)$

\section{Uso de máscara e ambu}

$\begin{array}{lllllll}\text { Sim } & 26 & (8,9 \%) & 25 & (8,6 \%) & 51 & (8,7 \%) \\ \text { Não } & 267 & (91,1 \%) & 267 & (91,4 \%) & 534 & (91,3 \%)\end{array}$

\section{Intubação traqueal}

Sim

$14 \quad(4,8 \%) \quad 11$

$(3,8 \%) \quad 25$

$(4,3 \%)$

Não

$279 \quad(95,2 \%) \quad 281$

$(96,2 \%) \quad 560$

$(95,7 \%)$

\section{Aspiração gástrica}

$\operatorname{Sim}$

$33 \quad(11,3 \%) \quad 46 \quad(15,8 \%) \quad 79$

$(13,5 \%)$ 
Resultados e discussão
Não
$260 \quad(88,7 \%) \quad 246$
$(84,2 \%) \quad 506$
$(86,5 \%)$

\section{Lavagem gástrica}

\begin{tabular}{cllllll} 
Sim & 32 & $(10,9 \%)$ & 41 & $(14,0 \%)$ & 73 & $(12,5 \%)$ \\
Não & 261 & $(89,1 \%)$ & 251 & $(86,0 \%)$ & 512 & $(87,5 \%)$ \\
TOTAL & 293 & $(50,1 \%)$ & 292 & $(49,9 \%)$ & 585 & $(100 \%)$ \\
\hline
\end{tabular}

O procedimento de aspirar as vias aéreas superiores dos recém-nascidos foi feito em 76,2\% (446) crianças e em 23,8\% (139) não foi necessário.

Os recém-nascidos que precisaram de oxigênio após o nascimento foram 197 $(33,7 \%)$, sendo predominantemente do sexo masculino, e os recém-nascidos que não precisaram de oxigênio foram $66,3 \%$ (388).

Observou-se que a maioria dos recém-nascidos não precisou da utilização da máscara, ou ambu, ou seja, 91,3\% (534). O uso da máscara e ambu foi observado em $8,7 \%$ (51) dos procedimentos de cuidado imediatos dos recém-nascidos.

Os dados mostraram que os recém-nascidos que não precisaram ser intubados após o nascimento foram 95,7\% (560). A intubação traqueal foi necessária em 4,3\% (25) recém-nascidos, dos quais 14 deles eram de sexo masculino e 11 de sexo feminino.

O procedimento de aspiração gástrica foi realizado em 13,5\% (79) crianças. Observou-se o predomínio desse procedimento no sexo feminino, com uma diferença de 4,5\% a mais, em relação ao sexo masculino. No total, 86,5\% (506) dos recémnascidos não precisaram fazer aspiração gástrica.

Em relação à lavagem gástrica, 87,5\% (512) crianças não precisaram do procedimento; 73 recém-nascidos precisaram de lavagem gástrica, dos quais 41 eram de sexo feminino e 32 de sexo masculino, totalizando $12,5 \%$. 
A ressuscitação do recém-nascido na sala de parto é um dos mais importantes desafios na prática pediátrica, pois terá repercussões por toda a vida, definindo a qualidade de vida do bebê, da família e o papel desse na sociedade. Um bebê com seqüelas, além de necessitar de cuidados relacionados à saúde por toda a vida, com internações freqüentes, necessitará de estimulação por tempo prolongado e de educação especial. Além disso, o afastamento dos pais do trabalho e a diminuição da capacidade produtiva do próprio indivíduo terão reflexos significativos na saúde da população com alto custo social (SOCIEDADE BRASILEIRA DE PEDIATRIA, s/d). 
Tabela 10 - Distribuição das intercorrências dos recém-nascidos de mães adolescentes, MATER. Ribeirão Preto SP, 2005

\begin{tabular}{|c|c|c|c|c|c|c|}
\hline VARIÁVEIS & \multicolumn{2}{|c|}{ Masculino } & \multicolumn{2}{|c|}{ Feminino } & \multicolumn{2}{|c|}{ TOTAL } \\
\hline $\begin{array}{l}\text { Intercorrências do neonato } \\
\text { Sim } \\
\text { Não }\end{array}$ & $\begin{array}{l}38 \\
255\end{array}$ & $\begin{array}{l}(13,0 \%) \\
(87,0 \%)\end{array}$ & $\begin{array}{l}28 \\
264\end{array}$ & $\begin{array}{r}(9,6 \%) \\
(90,4 \%)\end{array}$ & $\begin{array}{l}66 \\
519\end{array}$ & $\begin{array}{l}(11,3 \%) \\
(88,7 \%)\end{array}$ \\
\hline Total & 293 & $(50,1 \%)$ & 292 & $(49,9 \%)$ & 585 & $(100 \%)$ \\
\hline \multicolumn{7}{|l|}{$\begin{array}{l}\text { Tipos de intercorrências do } \\
\text { recém-nascido }\end{array}$} \\
\hline $\begin{array}{l}\text { Icterícia neonatal } \\
\text { Infecção neonatal } \\
\text { Taquipnéia transitória } \\
\text { Hipoglicemia neonatal } \\
\text { Desconforto respiratório } \\
\text { Síndrome de aspiração meconial } \\
\text { Fratura de clavícula } \\
\text { Conjuntivite química }\end{array}$ & $\begin{array}{l}19 \\
5 \\
4 \\
4 \\
2 \\
1 \\
1 \\
2\end{array}$ & $\begin{array}{r}(63,3 \%) \\
(13,2 \%) \\
(10,5 \%) \\
(10,5 \%) \\
(5,3 \%) \\
(2,6 \%) \\
(2,6 \%) \\
(5,3 \%)\end{array}$ & $\begin{array}{l}11 \\
5 \\
4 \\
3 \\
2 \\
2 \\
1 \\
0\end{array}$ & $\begin{array}{r}(36,7 \%) \\
(17,9 \%) \\
(14,3 \%) \\
(10,7 \%) \\
(7,1 \%) \\
(7,1 \%) \\
(3,6 \%) \\
(0 \%)\end{array}$ & $\begin{array}{l}30 \\
10 \\
8 \\
7 \\
4 \\
3 \\
2 \\
2\end{array}$ & $\begin{array}{r}(45,5 \%) \\
(15,2 \%) \\
(12,1 \%) \\
(10,6 \%) \\
(6,1 \%) \\
(4,5 \%) \\
(3,0 \%) \\
(3,0 \%)\end{array}$ \\
\hline TOTAL & 38 & $(57,6 \%)$ & 28 & $(42,4 \%)$ & 66 & $(100 \%)$ \\
\hline
\end{tabular}

Em relação às intercorrências, observou-se que 88,7\% (519) dos recémnascidos não apresentaram nenhum evento após o nascimento; $11,3 \%$, (66) RNs apresentaram algum tipo de intercorrência, dos quais 38 (13\%) foram de sexo masculino e $28(9,6 \%)$ do sexo feminino.

Em relação às intercorrências do recém-nascido, encontrou-se, em maior proporção, a icterícia neonatal com 45,5\% (30), sendo predominantemente presente no sexo masculino; infecção neonatal, em 15,2\% crianças (10); taquipnéia transitória, em 12,1\% (8) e hipoglicemia neonatal, em 10,6\% (7).

As demais intercorrências apresentaram menores proporções como: desconforto respiratório, $(6,1 \%)$; síndrome de aspiração meconial $(4,5 \%)$, fratura de clavícula $(3 \%)$, e conjuntivite química $(0,3 \%)$. 
Imediatamente após o nascimento, deve-se verificar o estado do recémnascido. Isso é parte integrante da assistência ao parto, sendo importante a abordagem unificada à assistência materna e neonatal. Os cuidados imediatos consistem em verificar a permeabilidade das vias aéreas, tomar providências para manutenção da temperatura corporal, clampear e cortar o cordão e colocar o bebê no seio o mais cedo possível (OMS, 1996).

O cuidado adequado do recém-nascido, após o nascimento, em sala de parto, é muito importante para prevenir o óbito neonatal e o estabelecimento de lesões especialmente cerebrais, que futuramente podem comprometer o crescimento e desenvolvimento neuropsicomotor (GUINSBURG; ALMEIDA, MIYOSI, 2004).

A icterícia neonatal é patologia muito comum no período neonatal; cerca de $60 \%$ dos recém-nascidos desenvolvem hiperbilirrubinemia detectável clinicamente nos primeiros dias de vida. Na maioria das vezes em que ocorre esse fenômeno transitório fisiológico, não se requer intervenção terapêutica (VIEIRA, 2004). 


\subsection{Associações entre as variáveis maternas e dos recém-nascidos}

Apresenta-se os resultados das associações entre o estado nutricional de mães adolescentes, dados obstétricos, com as condições clínicas dos recém nascidos.

Tabela 11 - Distribuição dos recém-nascidos quanto ao tipo de parto, intercorrências maternas e Apgar. MATER. Ribeirão Preto SP, 2005

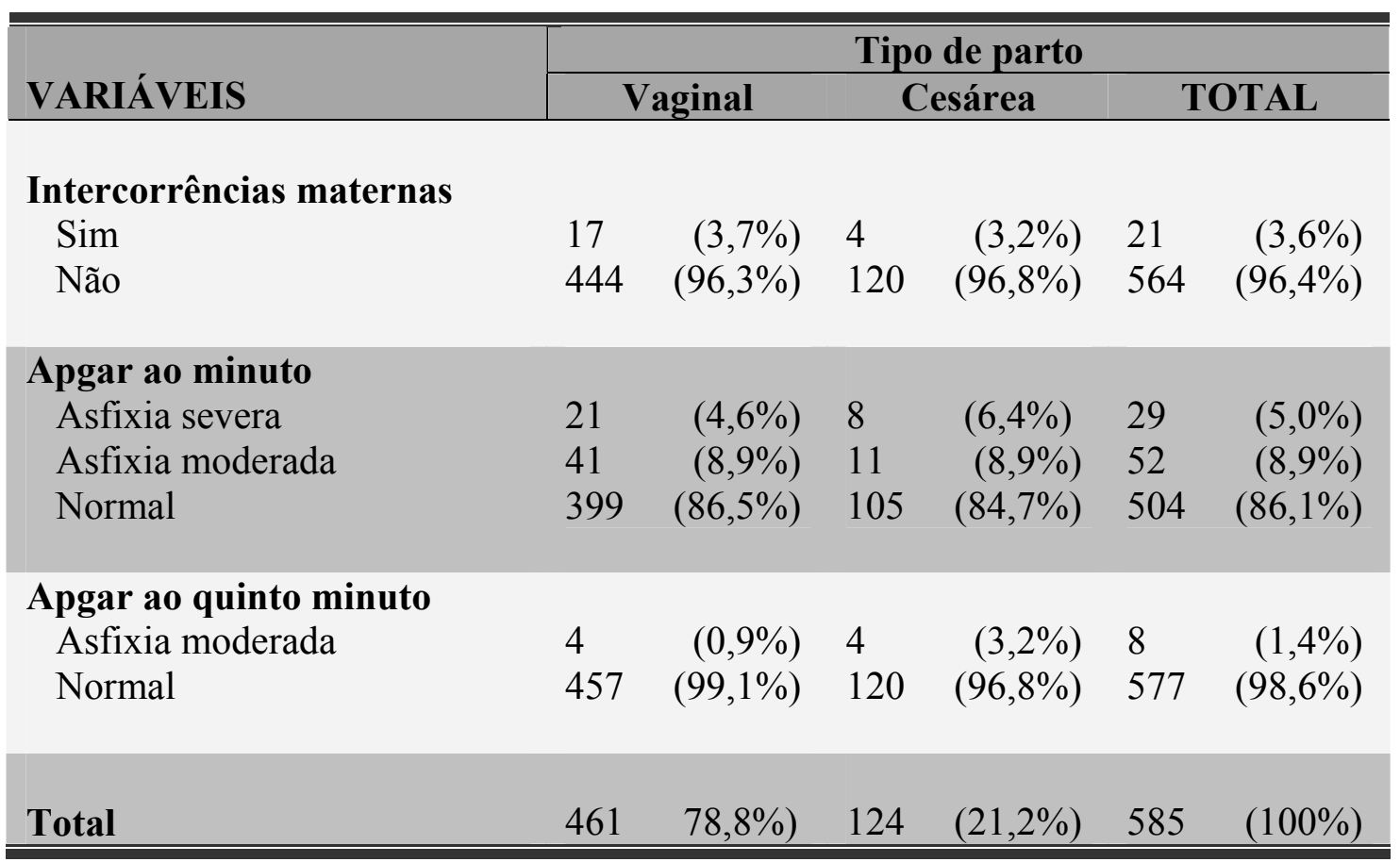

Relacionando o tipo de parto e as intercorrências maternas, encontrou-se, aqui, que o parto vaginal $(3,7 \%)$ e a cesariana $(3,2 \%)$ tiveram pouca diferença na probabilidade de apresentar alguma intercorrência com relação à mãe.

Quanto à análise do índice de Apgar do primeiro minuto com relação ao tipo de parto, identificou-se asfixia severa nos casos de cesariana, com $6,4 \%$, e no parto vaginal a percentagem diminui para $4,6 \%$. Ressalta-se que $86,5 \%$ das crianças nas- 
cidas de parto vaginal e $84,7 \%$ das crianças nascidas por cesariana tiveram Apgar normal ao primeiro minuto.

Em relação ao tipo de parto e o índice do Apgar do quinto minuto, encontrose asfixia moderada em $3,2 \%$ dos casos de cesariana e $0,9 \%$ nos partos vaginais.

$\mathrm{Na}$ análise do índice de Apgar do primeiro e do quinto minuto evidenciou-se que os melhores resultados são obtidos quando o parto é vaginal.

O objetivo da assistência imediata ao parto é proporcionar a todos os recémnascidos condições ótimas que visam sua adaptação à vida extra-uterina e preparada para intervir naqueles casos que apresentem condições que coloquem em risco sua vida (BRASIL, 2001).

Segundo a Sociedade Brasileira de Pediatria (s/d), de todos os partos, em torno de 5 a 10\% necessitam de alguma manobra de ressuscitação ao nascimento, e de 1 a $10 \%$ dos nascidos em hospitais precisam de ventilação com pressão positiva. Em todo o mundo, ocorrem por ano mais de 5 milhões de mortes no período neonatal, e em $20 \%$ dos casos, é a asfixia responsável por essas mortes.

O baixo índice de Apgar mostra depressão no estado geral do neonato, que poder ser devida à hipóxia, como também ao uso de drogas depressoras do sistema nervoso central, a traumatismos ou à inibição laríngea por estimulação como, por exemplo, uso de cateter (FUNAYAMA, 2005). 
Tabela 12 - Associação entre o estado nutricional de mães adolescentes e parâmetros clínicos dos recém nascidos, MATER. Ribeirão Preto SP, 2005

\begin{tabular}{|c|c|c|c|c|c|c|c|c|c|c|c|}
\hline \multirow[t]{2}{*}{ VARIÁVEIS } & \multicolumn{11}{|c|}{ Relação peso/estatura por idade gestacional das mães adolescentes $(n=585)$} \\
\hline & \multicolumn{2}{|c|}{ Baixo peso } & \multicolumn{2}{|c|}{ Normal } & \multicolumn{2}{|c|}{ Sobrepeso } & \multicolumn{2}{|c|}{ Obesidade } & \multirow[t]{2}{*}{$d^{*}$} & \multicolumn{2}{|r|}{ Total } \\
\hline \multicolumn{11}{|l|}{ Peso do recém-nascido } & \\
\hline Baixo peso ao nascer & 18 & $(6,7 \%)$ & 3 & $(1,6 \%)$ & 1 & $(1,5 \%)$ & 1 & $(1,5 \%)$ & & 23 & $(3,9 \%)$ \\
\hline Peso insuficiente ao nascer & 101 & $(37,5 \%)$ & 45 & $(24,5 \%)$ & 12 & $(18,2 \%)$ & 9 & $(13,6 \%)$ & $0208^{*}$ & 167 & $(28,5 \%)$ \\
\hline Peso adequado ao nascer & 149 & $(55,4 \%)$ & 127 & $(69,0 \%)$ & 53 & $(80,3 \%)$ & 50 & $(75,8 \%)$ & & 379 & $(64,8 \%)$ \\
\hline Macrossomia & 1 & $(0,4 \%)$ & 9 & $(4,9 \%)$ & 0 & $(0 \%)$ & 6 & $(9,1 \%)$ & & 16 & $(2,7 \%)$ \\
\hline \multicolumn{12}{|l|}{ Estatura do recém-nascido } \\
\hline Abaixo do normal & 66 & $(24,5 \%)$ & 23 & $(12,5 \%)$ & 10 & $(15,2 \%)$ & 6 & $(9,1 \%)$ & & 105 & $(17,9 \%)$ \\
\hline Normal & 196 & $(72,9 \%)$ & 152 & $(82,6 \%)$ & 53 & $(80,3 \%)$ & 55 & $(83,3 \%)$ & $0,111^{*}$ & 456 & $(77,9 \%)$ \\
\hline Acima do normal & 7 & $(2,6 \%)$ & 9 & $(4,9 \%)$ & 3 & $(4,5 \%)$ & 5 & $(7,6 \%)$ & & 24 & $(4,1 \%)$ \\
\hline \multicolumn{12}{|c|}{ Perímetro cefálico do recém-nascido } \\
\hline Abaixo do normal & 30 & $(11,2 \%)$ & 10 & $(5,4 \%)$ & 1 & $(1,5 \%)$ & 0 & $(0 \%)$ & & 41 & $(7,0 \%)$ \\
\hline Normal , & 227 & $(84,4 \%)$ & 160 & $(87,0 \%)$ & 60 & $(90,9 \%)$ & 55 & $(83,3 \%)$ & $0,111^{*}$ & 502 & $(85,8 \%)$ \\
\hline Acima do normal & 12 & $(4,5 \%)$ & 14 & $(7,6 \%)$ & 5 & $(7,6 \%)$ & 11 & $(16,7 \%)$ & & 42 & $(7,2 \%)$ \\
\hline \multicolumn{12}{|l|}{ Idade gestacional } \\
\hline Pré-termo & 12 & $(4,5 \%)$ & 9 & $(4,9 \%)$ & 4 & $(6,1 \%)$ & 1 & $(1,5 \%)$ & & 26 & $(4,4 \%)$ \\
\hline Termo & 256 & $(95,2 \%)$ & 170 & $(92,4 \%)$ & 59 & $(89,4 \%)$ & 62 & $(93,9 \%)$ & 0,03 & 547 & $(93,5 \%)$ \\
\hline Pós-termo & 1 & $(0,4 \%)$ & 5 & $(5,2 \%)$ & 3 & $(4,5 \%)$ & 3 & $(4,5 \%)$ & & 12 & $(2,1 \%)$ \\
\hline Total & 269 & $(46,0 \%)$ & 184 & $(31,5 \%)$ & 66 & $(11,3 \%)$ & 66 & $(11,3 \%)$ & & 585 & $(100 \%)$ \\
\hline
\end{tabular}

*Coeficiente de associaçă d de Somers, estatisticamente significativo quando $\mathrm{p} \leq 0,05$. 
Conforme apresentado na Tabela 12, observou-se associação estatisticamente significativa $(p \leq 0,05)$ entre o peso do recém-nascido e o peso da mãe. Encontrou-se que o baixo peso da mãe tem relação com baixo peso do recém-nascido, e que, à medida que aumenta o peso materno, menor é a probabilidade de a criança apresentar baixo peso ao nascer. Mães com peso normal (184, ou seja, 31,5\%) tiveram filhos com peso adequado ao nascer em 127 casos.

O baixo peso da mãe também mostrou relação com a estatura do recémnascido, sendo identificada fraca associação estatisticamente significativa $(d=0,11$; $\mathrm{p} \leq 0,05)$ de crianças com estatura abaixo do normal.

O perímetro cefálico mantém-se da mesma forma, com uma associação fraca estatisticamente significativa com relação ao estado nutricional da mãe $(d=0,11$; $\mathrm{p} \leq 0,05)$

Foi evidenciado que não existe associação estatisticamente significativa entre a idade gestacional e o estado nutricional da mãe $(\alpha \leq 0,05) 0,03$.

Furlan et al. (2003) concluíram que as adolescentes que terminaram a gravidez desnutridas tiveram maior número de recém-nascidos de baixo peso. A desnutrição materna no final da gravidez deve ser evitada, pois essa jovem mãe terá que amamentar um recém-nascido que tem grandes possibilidades de ter baixo peso. 
Griffiths et al. (1995) revelaram uma relação significativa $(\alpha<0,05)$ entre o estado nutricional da mãe no momento do parto e os parâmetros de desenvolvimento corporal do recém-nascido, sendo que o peso da mãe teve alta significância com peso do recém-nascido $(0,37)$, estatura do $\mathrm{RN}(0,34)$ e perímetro cefálico $(0,31)$.

Nos primeiros anos deste século, a taxa de nascimento pré-termo vem aumentando e constitui-se uma das principais causas da alta taxa de mortalidade por afecções perinatais, especialmente entre recém-nascidos de baixo peso para a idade gestacional. A ocorrência de anóxia em recém-nascidos pré-termo está relacionada, em parte, à vulnerabilidade do cérebro imaturo e ao ambiente extra-uterino (FUNAYAMA, 2005).

Com a finalidade de analisar a relação entre o índice de Apgar no primeiro e no quinto minuto e potenciais variáveis preditoras, elaborou-se um modelo de regressão logística múltipla, envolvendo as seguintes variáveis:

- resposta ou dependente: índice de Apgar, nos minutos 1 e 5, dicotomizado para incluir apenas duas categorias, asfixia (escores menores que 7) e normal (escores 7 ou mais);

- variáveis preditoras, todas dicotômicas: tipo de parto (vaginal e cesária, sendo cesária a categoria de referência), intercorrências maternas (sim e não, onde não é a categoria de referência) e idade gestacional (pré-termo e termo+pós-termo, sendo essa última a categoria de referência). 
O método de regressão escolhido para os dois índices foi por entrada forçada (forced entry method, no SPSS), uma vez que se pretendeu incluir todos os preditores simultaneamente que, em análise bivariada, mostraram-se estatisticamente significativos para um nível $\alpha=0,1$, apenas para o Apgar em 5 minutos. Os resultados dessa análise de regressão podem ser vistos nas Tabelas 13 e 14 seguintes.

Tabela 13 - Distribuição dos recém-nascidos quanto aos escores de Apgar de primeiro minuto e os preditores maternos. MATER. Ribeirão Preto SP, 2005

\begin{tabular}{|c|c|c|c|c|c|}
\hline \multirow[t]{2}{*}{ VARIÁVEIS } & \multicolumn{2}{|c|}{ Apgar $1^{\circ}$ minuto } & \multirow[t]{2}{*}{ TOTAL } & \multirow[t]{2}{*}{$\mathbf{R C}^{*}$} & \multirow[t]{2}{*}{$\overline{\mathbf{P}}$} \\
\hline & Normal & Asfixia & & & \\
\hline \multicolumn{6}{|l|}{ Tipo de parto } \\
\hline Vaginal & $399(86,6 \%)$ & $62(13,4 \%)$ & 461 & & \\
\hline Cesariana & $105(84,7 \%)$ & $19(15,3 \%)$ & 124 & 0,86 & 0,60 \\
\hline \multicolumn{6}{|l|}{ Idade gestacional } \\
\hline Pré-termo & $21 \quad(80,8 \%)$ & $5 \quad(19,2 \%)$ & 26 & & \\
\hline Termo & $483(86,4 \%)$ & $76 \quad(13,6 \%)$ & 559 & 1,57 & 0,38 \\
\hline \multicolumn{6}{|l|}{$\begin{array}{l}\text { Intercorrências } \\
\text { maternas }\end{array}$} \\
\hline Sim & $20 \quad(95,2 \%)$ & $(4,8 \%)$ & 21 & & \\
\hline Não & $485(85,8 \%)$ & $80 \quad(14,2 \%)$ & 564 & 0,294 & 0,239 \\
\hline TOTAL & $504(86,2 \%)$ & $81(13,8 \%)$ & $585(100 \%)$ & & \\
\hline
\end{tabular}

* RC - Razão de chances, estatisticamente significativa para $\mathrm{p}<0,05$

Tabela 14 - Distribuição dos recém-nascidos quanto aos escores de Apgar de quinto minuto e os preditores maternos, MATER. Ribeirão Preto SP, 2005

\begin{tabular}{|c|c|c|c|c|c|c|}
\hline \multirow{2}{*}{ VARIÁVEIS } & \multicolumn{3}{|c|}{ Apgar $5^{\circ}$ minuto } & \multirow[t]{2}{*}{ TOTAL } & \multirow[t]{2}{*}{$\mathrm{RC}^{*}$} & \multirow[t]{2}{*}{$\overline{\mathbf{P}}$} \\
\hline & Normal & & Asfixia & & & \\
\hline \multicolumn{7}{|l|}{ Tipo de parto } \\
\hline Vaginal & $457(99,1 \%)$ & 4 & $(0,9 \%)$ & 461 & 0,268 & 0,69 \\
\hline Cesariana & $120(96,8 \%)$ & 4 & $(3,2 \%)$ & 124 & & \\
\hline $\begin{array}{l}\text { Idade gestacional } \\
\text { Pré-termo }\end{array}$ & $24 \quad(92,3 \%)$ & 2 & $(7,7 \%)$ & 26 & 6,89 & 0,027 \\
\hline
\end{tabular}




\begin{tabular}{llllllll} 
Termo & $553(98,9 \%)$ & 6 & $(1,1 \%)$ & 559 & & \\
Intercorrências & & & & & & & \\
$\quad$ Sim & $20(95,2 \%)$ & 1 & $(4,8 \%)$ & 21 & 3,13 & 0,32 \\
Não & $557(98,8 \%)$ & 7 & $(1,2 \%)$ & 564 & & \\
& & & & & & \\
TOTAL & $577(98,6 \%)$ & 8 & $(1,4 \%)$ & $585(100 \%)$ & \\
\hline \hline
\end{tabular}

* RC - Razão de chances, estatisticamente significativa para $\mathrm{p}<0,05$

Para o índice de Apgar no 1 minuto, nenhum dos preditores mostrou-se estatisticamente significativo na análise de associação, para um $\alpha=0,05$. No entanto, para o Apgar de 5 minutos, o único preditor estatisticamente significativo, dentro de um nível de significância de 5\%, foi a idade gestacional, sendo o tipo de parto marginalmente significante $(p=0,069)$. No entanto, quando se observam as razões de chance ajustadas no modelo de regressão para o Apgar de 5 minutos, percebe-se que o parto vaginal exerce um efeito protetor no Apgar $(\mathrm{RC}=0,268)$, reduzindo em mais de $70 \%$ o risco de asfixia; no entanto, intercorrências maternas e parto pré-termo são fatores de risco para asfixia $(R C>1)$, não se podendo descartar o acaso para as intercorrências. 
Resultados e discussão 
Limites e Conclusões 


\section{Limites e conclusões}

Na realização deste estudo identificou-se limitações, dentre as quais ressaltamse:

- por se tratar de um estudo retrospectivo, de análise de prontuários, as anotações por parte da equipe da saúde são incompletas, muitas vezes discordantes ou omitidas, tornando difícil o acesso a certas informações, podendo prejudicar a assistência e futuras pesquisas. Sendo o prontuário um documento legal é importante ter anotações bem feitas e completas;

- não há cópia do cartão de gestantes no prontuário e perde-se informações importantes, como o peso inicial e ganho de peso durante a gestação. Também não se observou o uso de curvas de peso/idade gestacional e altura uterina/idade gestacional, conforme preconizado pelo Ministério da Saúde;

- a análise estatística de gestantes na faixa etária entre 10 e 14 anos ficou restrita pela reduzida amostra;

- não havia registro de algumas informações, principalmente de anamnese, das gestantes adolescentes que chegaram em trabalho de parto expulsivo, ou que tiveram parto domiciliar, mantendo-se incompletos os prontuários durante a internação.

No entanto, foi possível tirar importantes conclusões: 
- Das mães adolescentes, 96,2\% estavam na faixa etária entre 15 e 19 anos (idade no dia do parto) e 3,8\% entre as idades de $10-14$ anos; $83 \%$ das adolescentes grávidas não tinham vínculo oficial com seus parceiros e somente $15 \%$ terminaram os estudos de ensino médio;

- observou-se que $79 \%$ das adolescentes realizam o número adequado de controles pré-natal;

- somente $36,4 \%$ das adolescentes finalizaram a gravidez com peso normal, $46 \%$ com baixo peso, e 22,6\% com sobrepeso e obesidade. Esses dados mostraram relação estatisticamente significativa com relação ao peso, estatura e perímetro cefálico do bebê, sendo que a orientação nutricional é aspecto determinante para o desenvolvimento satisfatório do recém-nascido;

- a principal preocupação quanto ao estado nutricional tem sido em relação ao baixo peso e desnutrição, mas observou-se uma alta prevalência de sobrepeso e obesidade na população jovem, representando um sério problema. É, portanto, importante estimular novos estilos de vida e incorporação de hábitos alimentares mais saudáveis entre os jovens;

- o parto vaginal mostrou exercer efeito protetor no índice de Apgar, reduzindo em mais de $70 \%$ o risco de asfixia. Pode-se considerar o parto pré-termo com fator de risco para asfixia;

- a idade materna (adolescentes) tem sido associada à intercorrências durante a gravidez, parto e puerpério, mas não existem evidências que a idade materna, de forma isolada, determine comportamento obstétrico desfavorável do ponto de vista biológico. 
Referências 


\section{Referências}

AZEVEDO, G.D. et al. Efeitos da idade materna sobre os resultados perinatais. Revista Brasileira de Ginecologia e Obstetrícia, Rio de Janeiro, v.24, n.3, p.181-185, out./dez. 2002.

AZEVEDO, D.V.; SAMPAIO, H.A.C. Consumo alimentar de adolescentes atendidas em serviço de assistência pré-natal. Revista de Nutrição, Campinas, v.16, n.3, p.273 -280 , jul./set. 2003.

BARROS,J.C.R. Recém nascido normal: caracteres e assistência. In: NEME, B. Obstetrícia básica. 2. ed. São Paulo: Sarvier, 2000.

BITTAR, R.E. O que fazer para evitar a prematuridade? Revista Associação Médica Brasileira, São Paulo, v.47, n.1, p.15-16. jan./mar. 2001.

BRASIL. Ministério de Saúde. Banco de dados do sistema único de saúde. DATASUS. Informações de saúde. Brasília, 2005. Disponível em: www.datasus.gov.br. Acesso em: 05 jul. 2005.

BRASIL. Secretaria de atenção à saúde. Política nacional de atenção integral à saúde da mulher: princípios e diretrizes. Brasília: Ministério da Saúde, 2004.

BRASIL. Ministério da Saúde. Secretaria de políticas de saúde. Área técnica de saúde da mulher. Parto, aborto e puerperio: assistência humanizada a mulher. Brasília: Ministério da Saúde, 2001.

CAMELO JUNIOR., J.S.; MARTINEZ, F.E. Dilemas nutricionais no parto pretermo e repercussões na infância, adolescência e vida adulta. Jornal de Pediatria, Rio de Janeiro, v.81, n.1, s.1, p.33-42, 2005.

CAMIÑA, R.S., Prevalência de baixo peso ao nascer e fatores associados nos municípios da $7^{\text {a }}$ reginal de saúde de Jacoba, Santa Catarina, Período 1995 a 
1999. 2005. Dissertação (Mestrado) - Universidade do Oeste de Santa Catarina, Joaçaba, 2005.

CARNIEL, E.F., et al., características das mães adolescentes e de seus recém nascidos e fatores de risco para a gravidez na adolescência em Campinas SP- Brasil. Revista Brasileira Materno Infantil, Recife, v.6, n.4, p. 419- 426, oct/dez. 2006.

CHATKIN,N.M, MENEZES, A.M.B. The association between low birthweight and asthma: a systematic literature review. Revista Panamericana de Salud Pública, Washington, v.17, n.2, p102-109. Feb. 2005.

COSTA, M.C.O.; NETO, A.F.O. Abordagem nutricional de gestantes e nutrizes adolescentes: estratégia básica na prevenção de riscos. Jornal de Pediatria, Rio de Janeiro, v.75, n.3, p.161- 166,1999.

CRUZ, E.C. Mortalidad materna y perinatal en adolescentes. Revista Cubana de Obstetricia y Ginecología, La Habana, v.28, n.1, p.5-10. 2002

CUNHA, A.A. et.al. Fatores associados à asfixia neonatal. Revista Brasileira de Ginecologia e Obstetrícia, Rio de Janeiro, v.26, n.10, p.799-805, nov./dec. 2004.

DIAS, M.A.B.; DESLANDES, S.F. Cesarianas: percepção de risco e sua indicação pelo obstetra em uma maternidade pública no Município de Rio de Janeiro. Cadernos de Saúde Pública, Rio de Janeiro, v.20, n.1, p.109- 116, jan/feb. 2004

\section{DIRECCIÓN DE SALUD MATERNO INFANTIL, Gráfica de incremento de peso} para embarazadas, Normograma de Rosso. Buenos Aires: Revista Hospital Materno Infantil Ramón Sarda, 1996. p.123- 126.

EBERLE,A.S. Interação entre a analgesia de parto e o se resultado: avaliação pelo peso e o índice de Apgar do recém nascido. Revista Brasileira de Anestesiologia, Campinas, v.56, n.4, p.343 - 351, set/ago. 2006. 
EISENSTEIN, E. et.al. Nutrição na adolescência. Jornal de Pediatria, Rio de Janeiro v.76, n.3, p.263-273, nov./dec. 2000.

FAUNDES, A.; PARPINELLI, M.A.; PEREIRA, B.G. Avaliação Clínica Fetal. In: NEME, B. Obstetrícia básica. 2. ed. São Paulo: Sarvier, 2000.

FERNANDES, S.I. Gravidez de adolescência. Adolescência Latinoamericana, Porto Alegre, v.3, n.2, p.0-0 nov. 2002.

FREIRE, T.M. et al. Efeitos do consumo de bebida alcoólica sobre o feto. Revista Brasileira de Ginecologia e Obstetrícia, Rio de Janeiro, v.27, n.7, p.376 - 381, 2005.

FUNAYAMA,C.A.R. Anoxia neonatal e seqüelas neurológicas. São Paulo: Átomo, 2005.

FUNDO DAS NAÇÕES UNIDAS PARA A INFANCIA. UNICEF. Relatório da situação da infância e da adolescência brasileira. Diversidade e equidade: pela garantia dos direitos de cada criança e adolescentes. Brasília, 2003. Disponível em: www.unicef.org. Acesso em: 25 de Abril 2007.

FURLAN, J.P. et.al. A influência do estado nutricional da adolescente grávida sobre o tipo de parto e o peso de recém nascido. Revista Brasileira de Ginecologia e Obstetrícia, Rio de Janeiro, v.25, n.9, p.625- 630, 2003.

GAMA, S.G.N. et.al. Gravidez na adolescência como fator de risco para baixo peso ao nascer no município de Rio de Janeiro 1996 a 1998. Revista Saúde Pública, Rio de Janeiro, v.15, n.2, p.74 -80, 2001.

GAMA, S.G.N. et al. Fatores associados à assistência pré-natal precária em uma amostra de puérperas adolescentes em maternidade do Município do Rio de Janeiro 1999- 2000. Cadernos de Saúde Pública, Rio de Janeiro, v.20, n.1, p.101- 111, 2004. 
GODFREY, K.M.; BARKER, D.J.P. Fetal nutrition and adult disease. Americam Journal Clinical Nutrition, São Paulo, v.71, n.5, p.1344-1352, May. 2000.

GOMEZ, G.R.; ANZARDO, R.B.R. La nutrición: un aspecto importante en la calidad de vida de la mujer. Revista Brasileira de Saúde Materno Infantil, Recife, v.3, n.2, p.215-219, abr./jun. 2003.

GOLDENBERG, P.; FIGUEIREDO, T.M.; SILVA, R.S. Gravidez na adolescência, pré-natal e resultados perinatais em Montes Claros, Minas Gerais, Brasil. Cadernos de Saúde Pública, Rio de Janeiro, v.21, n.4, p.1077-1086, jul./ago. 2005.

GRANDI, C.A. Relación entre la antropometría meterna y la ganancia de peso gestacional com el peso de nascimiento, y riesgos de bajo peso al nacer, pequeño para edad gestacional y prematurez en uma población urbana de Buenos Aires. Archivos Latinoamericanos de Nutrición, Caracas, v.53, n.4, p.369-375, dic. 2003.

GRIFFITHS, E.A. et al. Relación entre el estado nutricional de madres adolescentes y el desarrollo neonatal, Boletín oficina sanitaria panamericana, Chile, v.118, n.6, p. $488-498.1995$.

GUINSBURG, R.; ALMEIDA, M. F.B.; MIYOSI, M.H. Reanimação do recém nascido em sala de parto In: SANTOS, A.M.N.; ALMEIDA, M.F.B. Diagnostico e tratamento em neonatología. São Paulo: Atheneu, 2004. p. 31-37.

HAIDAR, F. H.; OLIVEIRA, U. F.; NASCIMENTO, L.F.C. Escolaridade materna: correlação com os indicadores obstétricos. Cadernos de Saúde Pública, Rio de Janeiro, v.17, n.4, p.1025 - 1029, jul/ago. 2001.

IDENTIFICACION de factores de riesgo asociados a bajo y deficit de peso al nacer. Santa Fé de Bogotá: Ed.Universitaria, 1999. 57p.

INSTITUTO BRASILERO DE GEOGRAFÍA E ESTATISTICA. IBGE. Censo demográfico 2000: primeiros resultados da amostra. Rio de Janeiro, 2000. 
ISSLER, J.R. Embarazo en la adolescencia. Revista de Post grado de la Catedra via Medicina, Corrientes , n.170, p.11-23, agos. 2001.

MACCHIAVERNI, L.M.L.; BARROS FILHO, A.A., Perímetro cefálico: porque medir sempre. Revista de Medicina, Ribeirão Preto, v. 32, p.595- 609, out./dez. 1998.

MAGALHÃES, M.L.C. et.al. Gestação na adolescência precoce e tardia- há diferença nos riscos obstétricos?. Revista Brasileira de Ginecologia e Obstetrícia, Rio de Janeiro, n.28, v.8, p.446-452. 2006.

MARIOTONI, G.G.B.; BARROS FILHO, A.A. A gravidez na adolescência é fator de risco para o baixo peso ao nascer? (Brasil). Revista Chilena de Pediatria, Santiago de Chile, v.71, n.5, set. 2000.

OLIVEIRA, N.R. Perfil de grávidas e mães adolescentes: estudo psicossocial de adolescentes usuárias de um serviço público de pré-natal e maternidade. 1999. Tese (Doutorado em Psicologia Social) - Instituto de Psicologia, Universidade de São Paulo, São Paulo, 1999.

OLIVEIRA, S.M.J.; MIQUILINI, E.C. Freqüência e critérios para indicar a episiotomia. Revista Escola de Enfermagem USP, São Paulo, v.39, p.288- 295, 2005.

ORGANIZAÇÃO MUNDIAL DE SAÚDE. OMS. Maternidade segura: assistência ao parto normal: um guia pratico. Genebra: OMS, 1996.

ORGANIZACION MUNDIAL DE LA SALUD. OMS. Saúde reprodutiva: estratégia para acelerar el avance hacia el logro de los objetivos y metas internacionales de desarrollo. Washington, 2004.

PARENTI, P.W. Gravidez na adolescência: análise do conhecimento construído pela enfermagem. 2002. 111f. Dissertação (Mestrado em Saúde Pública)- Escola de Enfermagem de Ribeirão Preto, Universidade de São Paulo, Ribeirão Preto, 2002. 
PAULICS, V.; FERRON, F.M. Atenção à gravidez na adolescência. São Paulo: FUNDAÇÃO PERSEU ABRAMU, 2006. Disponível em: http://www2.fpa.org.br/portal/modules/news/article.php?storyid=2638 $\quad$ Acceso em:12 jul. 2006.

PINTO e SILVA, J.L.; CHINAGLIA, M.L.M. Aspectos Médicos Sociais: gravidez na Adolescência. In: NEME,B. Obstetrícia básica. 2. ed. São Paulo: Sarvier, 2000. p. $1195-1201$.

PINTO e SILVA, J.L. Anomalias da Evolução da Gestação: prematuridade: aspectos obstétricos. In: NEME,B. Obstetrícia básica. 2. ed. São Paulo: Sarvier, 2000. p.561572.

REDE FEMINISTA DE SAÚDE. Dossiê Adolescentes - Saúde sexual saúde reprodutiva: Belo $1999 . \quad$ Disponível em: http://www.redesaude.org.br/dossies/dossiessr.html. Acesso em: 11 jan. 2006.

RIBEIRO, A. et al. Relação do Apgar em recém nascido a termo com a eficiência da mamada. Revista de Fonoaudiologia, Cidade, v.4, n.1, p.1-3, 2004.

RIBEIRO, E. R. et al. Comparação entre duas coortes de mães adolescentes em município do Sudeste do Brasil. Revista de Saúde Pública, São Paulo, v.34, n.2, p. $136-142$, abr. 2000.

RIBEIRO, L.C. et al. Nutrição e Alimentação na Gestação. Compacta: temas em nutrição e alimentação. São Paulo, v.3, n.2, p.0-0, 2002.

RUZANY, M.H. Mapa da situação de saúde do adolescente no município de Rio de Janeiro. 2000. 111f. Tese (Doutorado) - Escola Nacional de Saúde Pública, Fundação Oswaldo Cruz, Rio de Janeiro, 2000. 
SABROZA, A.R. et al. Perfil sócio-demográfico e psicossocial de puérperas adolescentes do Município do Rio de Janeiro, Brasil - 1999-2000. Cadernos de Saúde Pública, Rio de Janeiro, v.20, n.1, p 112- 120, 2004.

SALAZAR, F.R.S. et.al. Índice de masa corporal en embarazadas adolescentes. Revista Cubana de Medicina General Integral, La Havana, v.19, n.1, p.0-0. 2003.

SCHWARCZ, R. et al. El cuidado prenatal. Guía para la práctica del cuidado preconcepcional y del control prenatal. Argentina. Ministério de la salud, 2001.

SOCIEDADE BRASILEIRA DE PEDIATRIA. A importância de atendimento adequado ao recém nascido na sala de parto. Rio de Janeiro, s/d. Disponível em: http://www.sbp.com.br/show_item2.cfm?id_categoria=24\&id_detalhe=863\&tipo_det $\underline{\text { alhe }=\mathrm{S}}$.Acceso em: 12 fevereiro 2007.

SZWARCWALD, C.L. et.al. Desigualdades de renda e situação de saúde: o caso de Rio de Janeiro. Cadernos de Saúde Pública, Rio de Janeiro, v. 15, n. 1, p.15-28, 1999.

TAKITO, M.Y.; BENICIO, M.H.A.; LATORRE, M.R.D.O. Postura materna durante a gestação e sua influência sobre o peso ao nascer. Revista de Saúde Pública, São Paulo, v.39, n.3, p.325-332, jun. 2005.

VASCONCELOS, M.G.L. Implantação de um grupo de apoio à mãe acompanhante de recém nascido pré-termo e de baixo peso em um hospital amigo da criança na cidade de Recife/PE. 2001. 95f. Tese (Doutorado em Saúde Pública) Escola de Enfermagem de Ribeirão Preto, Universidade de São Paulo, Ribeirão Preto, 2001.

VIERA, A. A. et al. O uso da fototerapia em recém-nascidos: avaliação da prática clínica. Revista Brasileira Saúde Materno Infantil, Recife, v.4, n 4, p.359- 366, oct/dez. 2004. 
VIERA, E.M. Políticas públicas e concentração no Brasil. In: BERQUÓ E. (Org.). Sexo \& Vida: panorama da saúde reprodutiva no Brasil. São Paulo: Editora Unicamp, 2003. p.151- 196.

VILLELA, W. V.; ARILHA, M. Sexualidade, gênero e direitos sexuais e reprodutivos. In: BERQUÓ E. (Org.). Sexo \& Vida: panorama da saúde reprodutiva no Brasil. São Paulo: Editora Unicamp, 2003. p. 95 - 150.

YAZLLE, M.E.H.D. et.al. A adolescente grávida: alguns indicadores sociais. Revista Brasileira de Ginecologia e Obstetrícia, Rio de Janeiro, v.24, n.9, p.609-614, oct. 2002.

WONG.,D.,L. Enfermagem Pedriátrica: elementos essenciais à intervenção efetiva. In: PROMOÇÃO da saúde do recém nascido e da família. Rio de Janeiro: Guanabara Koogan, 1999. p.162-163.

ZUCCHI, M. Depressão na gravidez e prematuridade: Aspectos epistemológicos da investigação. Cadernos de Saúde Pública, Rio de Janeiro, v. 15, n.1, p. 89 - 97 jan/mar. 1999. 
Apêndice 


\author{
APÊNDICE A \\ UNIVERSIDADE DE SÃO PAULO \\ ESCOLA DE ENFERMAGEM DE RIBEIRÃO PRETO/USP
}

\title{
Gravidez na adolescência: análise de resultados nutricionais, obstétricos e neonatais
}

$\mathrm{N}^{\circ}$ de prontuário

$\mathrm{N}^{\mathrm{o}}$ do sujeito

Data da coleta

Nome do sujeito:

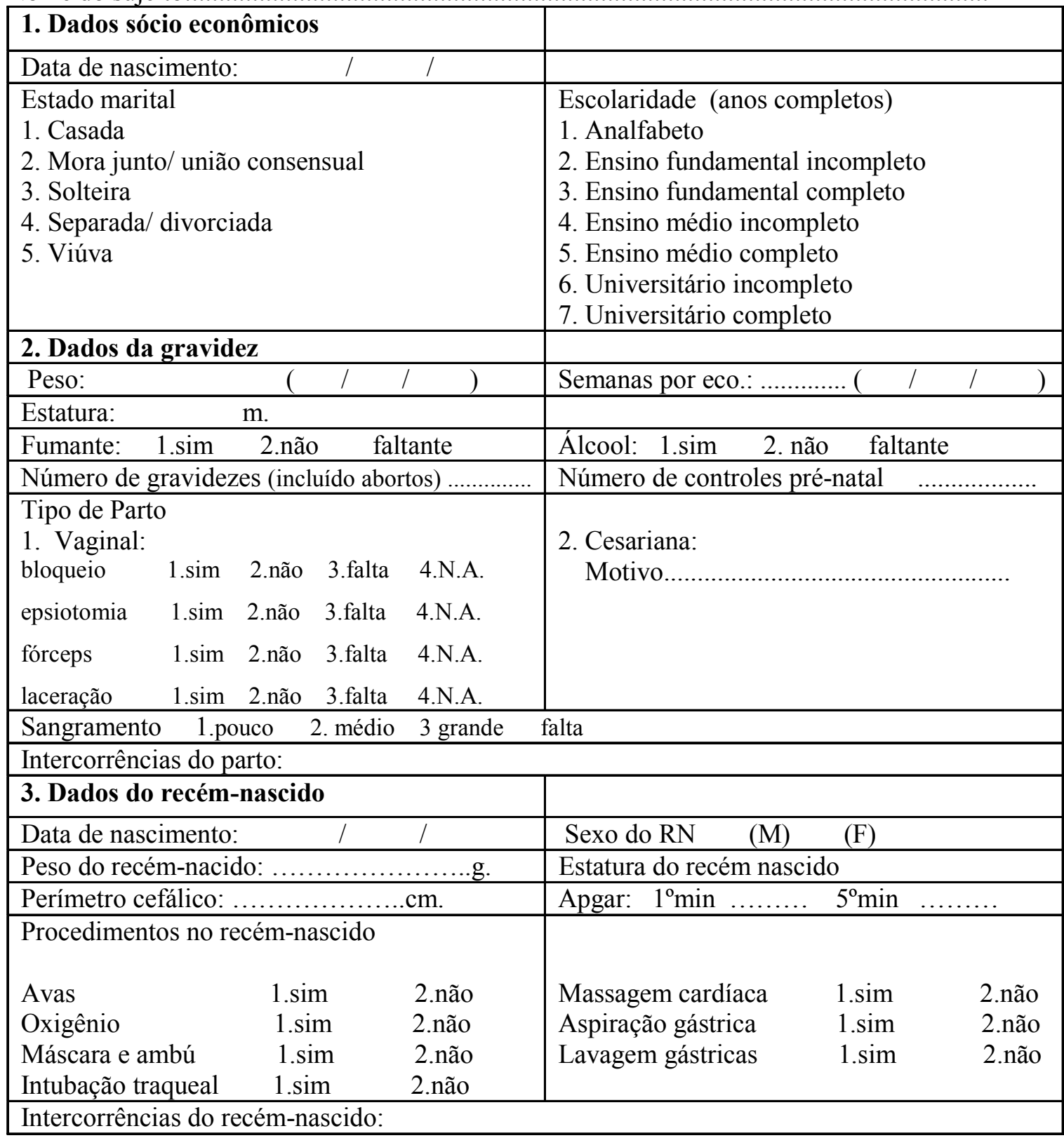


Anexos 
ANEXO A

NOMOGRAMA DE ROSSO

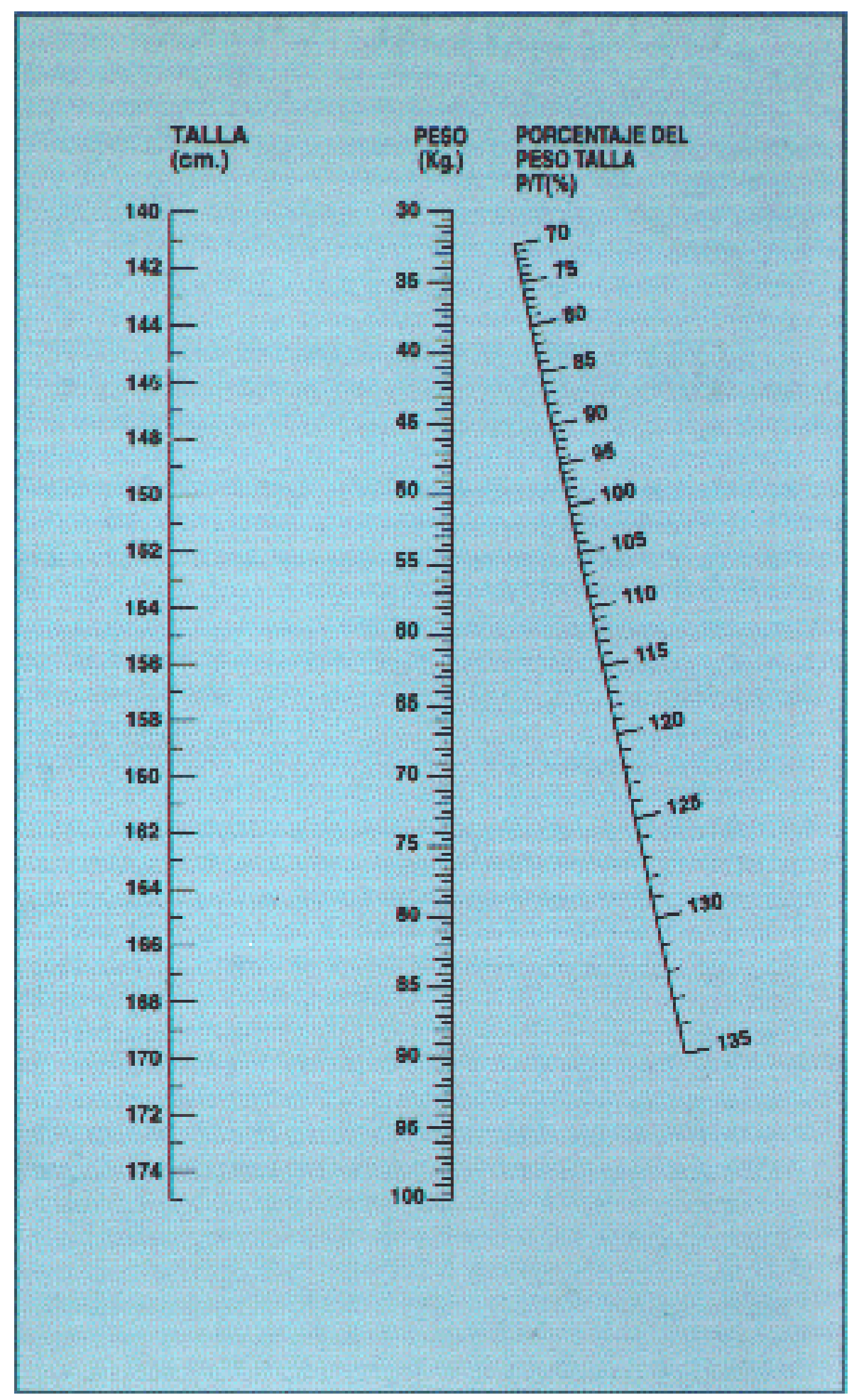




\section{CURVA DE ROSSO}

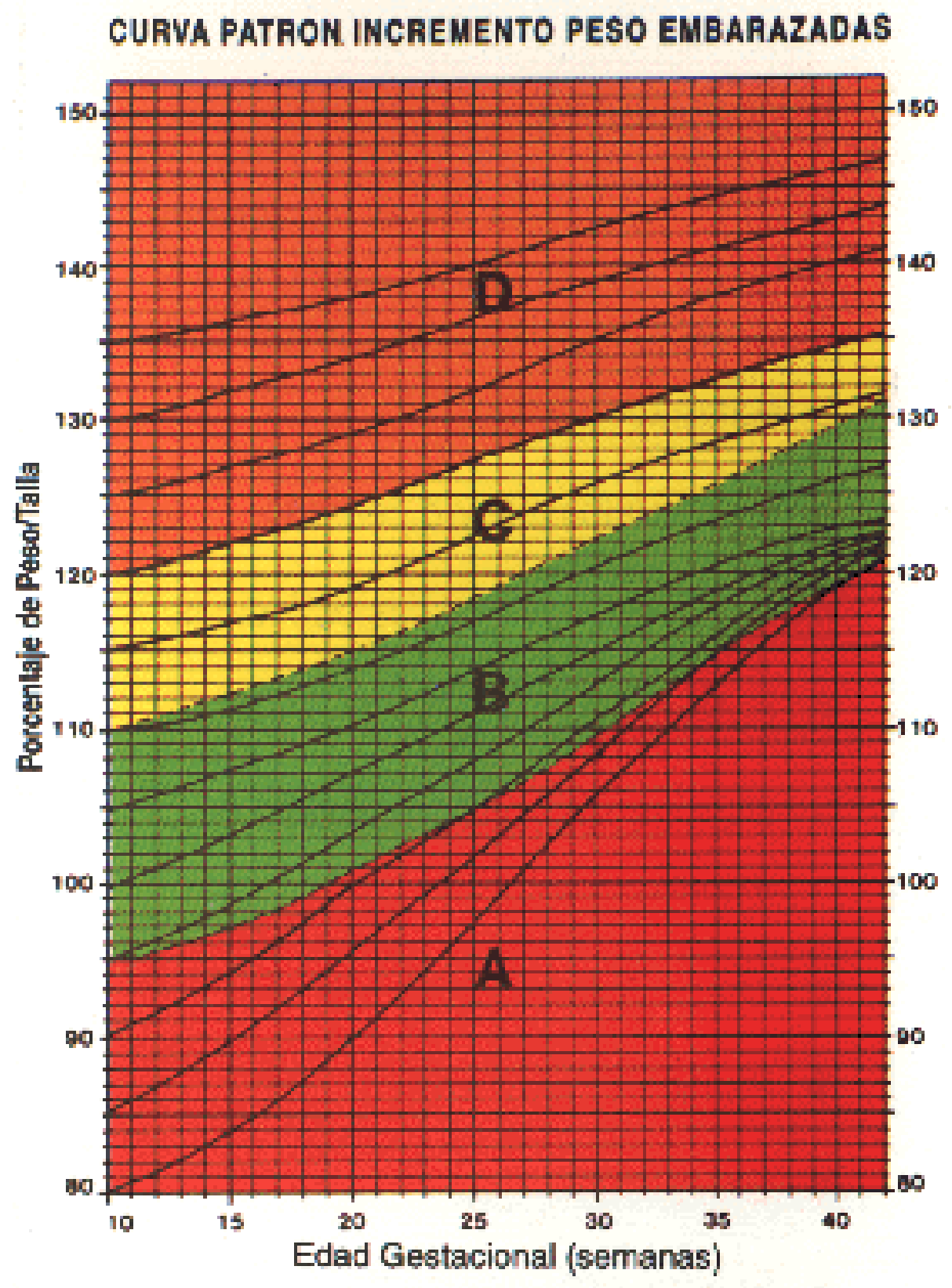

CATEGORIAS DE ESTADO NUTRICIONAL

\begin{tabular}{|c|c|}
\hline Bajo Peso & C \\
\hline Normal & D \\
\hline
\end{tabular}

FONTE: Rosso P., Mardones S. P. Chile 1986 Gráfica de incremento de poso para embarazadas Dirección de Salud Materno Infantil. 

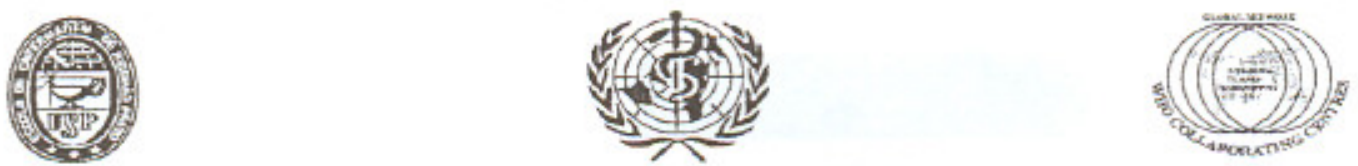

ESCOLA DE ENFERMAGEM DE RIBEIRÃO PRETO - UNIVERSIDADE DE SÃO PAULO CFETRO COI.ABORADOR DA ORGANI7.AC,ÄO MUNDIAI. DA SAÜDF, PARA O DESENVOLVIMENTO DA PESQUISA EM ENFERMAGEM

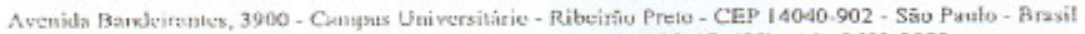
FAX: (SS) - $16-3633-3271$; $3602-4419 ;$ TELEFONE: (55) - 16-3602-3382

\section{COMITÉ DE ÉTICA EM PESQUISA DA EERPIUSP}

Of.CEP-EERP/USP - 082/2006

Ribeirão Preto, 18 de maio de 2006.

Prezada Senhora,

Comunicamos que o projeto de pesquisa, abaixo especificado, foi analisado e considerado APROVADO pelo Comité de Ética em Pesquisa da Escola de Enfermagem de Ribeirăo Preto da Universidade de São Paulo, em sua $86^{a}$ Reuniāo Ordinária, realizada em 17 de maio de 2006.

Protocolo: $n^{\circ} 0666 / 2006$

Projeto: Estado nutricional de adolescentes grávidas assistidas na Maternidade do Complexo Aeroporto e resultados clinicos dos recém-nascidos

Pesquisadores: Maria José Clapis (Orientadora)

Cláudia Rios Cataño (Mestranda)

Em atendimento à Resoluçāo 196/96, deverá ser encaminhado ao CEP o relatório final da pesquisa e a publicaçăo de seus resultados, para acompanhamento, bem como comunicada qualquer intercorrência ou a sua interrupçāo.

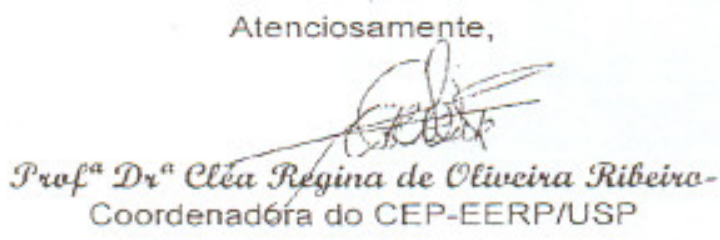

IIma. Sra.

Prof ${ }^{\mathrm{D}} \mathrm{Dr}^{\mathrm{A}}$ Maria José Clapis

Dept ${ }^{\circ}$ de Enfermagem Materno-Infantil e Saúde Pública

Escola de Enfermagem de Ribeirāo Preto - USP 